\title{
Impaired neurogenesis, learning and memory and low seizure threshold associated with loss of neural precursor cell survivin
}

\author{
Vanessa Coremans ${ }^{1}$, Tariq Ahmed², Detlef Balschun², Rudi D'Hooge ${ }^{2}$, Astrid DeVriese ${ }^{1}$, Jonathan Cremer ${ }^{1}$, \\ Flavia Antonucci ${ }^{3}$, Michaël Moons ${ }^{1}$, Veerle Baekelandt ${ }^{5}$, Veerle Reumers ${ }^{5}$, Harold Cremer ${ }^{6}$, Amelia Eisch ${ }^{7}$, \\ Diane Lagace ${ }^{8}$, Tom Janssens ${ }^{1}$, Yuri Bozzi ${ }^{4,9}$, Matteo Caleo ${ }^{4}$, Edward M Conway ${ }^{1,10^{*}}$
}

\begin{abstract}
Background: Survivin is a unique member of the inhibitor of apoptosis protein (IAP) family in that it exhibits antiapoptotic properties and also promotes the cell cycle and mediates mitosis as a chromosome passenger protein. Survivin is highly expressed in neural precursor cells in the brain, yet its function there has not been elucidated.
\end{abstract}

Results: To examine the role of neural precursor cell survivin, we first showed that survivin is normally expressed in periventricular neurogenic regions in the embryo, becoming restricted postnatally to proliferating and migrating NPCs in the key neurogenic sites, the subventricular zone (SVZ) and the subgranular zone (SGZ). We then used a conditional gene inactivation strategy to delete the survivin gene prenatally in those neurogenic regions. Lack of embryonic NPC survivin results in viable, fertile mice (Survivin ${ }^{\text {Camcre) }}$ ) with reduced numbers of SVZ NPCs, absent rostral migratory stream, and olfactory bulb hypoplasia. The phenotype can be partially rescued, as intracerebroventricular gene delivery of survivin during embryonic development increases olfactory bulb neurogenesis, detected postnatally. Survivin ${ }^{\text {Camcre }}$ brains have fewer cortical inhibitory interneurons, contributing to enhanced sensitivity to seizures, and profound deficits in memory and learning.

Conclusions: The findings highlight the critical role that survivin plays during neural development, deficiencies of which dramatically impact on postnatal neural function.

\section{Background}

In the adult, two major, well-defined neurogenic regions persist [1]. In the subventricular zone (SVZ), neural precursor cells (NPCs) that arise mostly from the embryonic lateral ganglionic eminence (LGE) [2], continuously proliferate, and then migrate tangentially along the rostral migratory stream (RMS) towards the olfactory bulb (OB) where they differentiate into granular and periglomerular inhibitory interneurons [3]. In the subgranular zone (SGZ) of the hippocampus, newborn NPCs also migrate, but for shorter distances, into the granule cell layer, where they become excitatory granule cells [4]. From these neurogenic sites, adult-generated neurons

\footnotetext{
* Correspondence: emconway@interchange.ubc.ca
${ }^{1}$ KU Leuven, VIB Vesalius Research Center (VRC), Herestraat 49, Gasthuisberg

* Correspondence: emconway@interchange.ubc.ca
'KU Leuven, VIB Vesalius Research Center (VRC), Herestraat 49, Gasthuisberg O\&N1, B3000 Leuven, Belgium
}

(c) 2010 Coremans et al; licensee BioMed Central Ltd. This is an Open Access article distributed under the terms of the Creative Commons Attribution License (http://creativecommons.org/licenses/by/2.0), which permits unrestricted use, distribution, and reproduction in any medium, provided the original work is properly cited. synaptic contacts and functional connections [6,7]. Decreased neurogenesis induced by prenatal or postnatal stresses is implicated in the development of seizures and disorders in learning, memory and cognition $[8,9]$. The possibility of preventing onset or progression of these neural diseases by therapeutically enhancing neurogenesis [10-15] is prompting efforts to delineate the mechanisms and regulatory factors underlying NPC survival, proliferation, differentiation, migration and function. Indeed, numerous neuro-regulatory transcription factors, growth factors and receptors have been identified and characterized (reviewed in [16-19]). However, in spite of advances, effective approaches to prevent and treat diseases of the central nervous system are lacking, underlining the urgent need to develop better models to elucidate the molecular mechanisms regulating 
integration of new neurons in the developing and adult brain. Survivin is a member of the inhibitor of apoptotis protein (IAP) family, that also promotes the cell cycle and is a chromosome passenger protein [20,21]. During embryonic development, it is expressed by several tissues, but is particularly prominent in the nervous system [22]. Inactivation of the survivin gene in neuroepithelial cells early in development [23] results in massive apoptosis throughout the central nervous system, with total destruction of the architecture of the brain and lethality. The severity of this phenotype precluded investigators from delineating the specific role of neural precursor cell survivin on postnatal neural function.

Therefore, to elucidate the properties of survivin in neural development and function, we inactivated the survivin gene in NPCs in the late-midterm murine embryo and evaluated the effects post-natally. By this approach, we generated a unique in vivo mouse model in which reduced neurogenesis is associated with epilepsy and profound deficits in learning and memory. Pilot rescue studies suggest that embryonic administration of survivin may enhance neurogenesis. The findings highlight the critical role that survivin plays during neural development, deficiencies of which dramatically impact on postnatal neural function.

\section{Results}

Survivin is expressed in precursor cells in the neurogenic areas of the brain

In situ hybridization using a probe against full length survivin allowed assessment of the spatiotemporal expression of survivin during embryonic development. Survivin mRNA was detected in the neurogenic areas of the dorsal and ventral telencephalon surrounding the ventricles (neocortex, medial and lateral ganglionic eminences (MGE and LGE, respectively)) (Figure 1A). At E12.5, expression of survivin overlapped with Dlx1, a marker for mitotic cells in the MGE and LGE [24] (Figure 1A, D) and neurogenin 2 (Ngn2) [25], a marker for dividing precursors in the neocortex (Figure 1A, C). There was minimal overlap with Dlx5 (Figure 1B), which is primarily expressed by postmitotic cells in the mantle zone of the MGE and LGE, less so in mitotic cells in the SVZ, and almost absent in the ventricular zone [26]. By E17.5, survivin was additionally expressed in the rostral migratory stream (RMS) and at the center of the olfactory bulb (OB) (Figure 1G, I, K). Survivin mRNA was also present in the retina and lens of the developing eye (not shown).

Postnatally, survivin expression was restricted largely to rapidly proliferating cells [21] and migrating NPCs [27]. At P7, survivin mRNA was detected in the SVZ, the RMS, the $O B$, and the dentate gyrus (DG) (Figure $2 \mathrm{~A}, \mathrm{C}, \mathrm{D}, \mathrm{E})$. Within the SVZ, survivin was not expressed in the ependymal cells immediately adjacent to the lateral ventricle (Figure 2C, D). During the first two postnatal weeks, survivin mRNA was also detected in granule cell precursors in the external germinal layer (EGL) of the developing cerebellum (Figure 2A). In the adult brain, survivin expression remained restricted to proliferating and migrating precursor cells in the SVZ, the RMS, and the subgranular zone (SGZ) of the DG (Figure 2F, H).

In both the SVZ (Figure 2J-L) and the SGZ of the DG (Figure 2M-O), $>95 \%$ of survivin expressing cells were positive for the proliferation marker PCNA, while at both sites, $25-50 \%$ of PCNA positive cells expressed survivin. Thus, survivin expressing cells represent a subpopulation of the mitotically active cells. Doublecortin (DCX), present in immature, migrating neuroblasts [28] also overlapped with survivin in the SVZ, the RMS and the SGZ. However, similar to PCNA, not all DCX positive cells expressed survivin, indicating that survivin is restricted to a subpopulation of cells in the SVZ-RMS (not shown). Mature neuronal marker NeuN [29] immunoreactivity did not overlap with survivin, consistent with the lack of survivin expression by mature neurons (Figure 2C-E).

Overall, survivin expression is restricted during fetal development to NPCs in neurogenic regions of the telencephalon, of which a fraction populates the major neurogenic regions of the postnatal brain, i.e. the SVZ and the SGZ. Within these neurogenic regions, a subpopulation of NPCs continues to express survivin, which is downregulated once the cells differentiate into neurons. In both the embryo or adult, survivin is not detected in neurons in the cortex, OB, or hippocampus.

\section{In vivo Prenatal Survivin gene inactivation}

To study the in vivo role of NPC survivin, we generated mice in which the survivin gene is inactivated in the neurogenic regions of the brain prenatally. Mice expressing cre recombinase driven by the CamKII $\alpha$ promoter $[30,31]$ were bred with mice in which the entire survivin gene is flanked by loxP sites [32]. The resultant CamKIIo-cre:survivin ${ }^{\text {lox/lox }}$ (referred to as Survivin ${ }^{\text {Camcre }}$ ) mice were born in the expected Mendelian distribution, i.e. there was no evidence of embryonic lethality.

We confirmed previous reports of cre recombinase activity in the CAMKII $\alpha$-cre embryos and mice [30,31] by breeding the CAMKII $\alpha$-cre mice with the ROSA26 reporter mice, followed by immunohistochemical detection of GFP. Cre recombinase activity at E12.5 was detected prominently in the ventral telencephalon (ganglionic eminences), but less in the dorsal telencephalon, and not in the eye (Additional file 1: Supplemental Figure S1). Postnatally, it was restricted to postmitotic NeuN positive neurons in the hippocampus and cortex, with lower levels in the striatum, thalamus, 


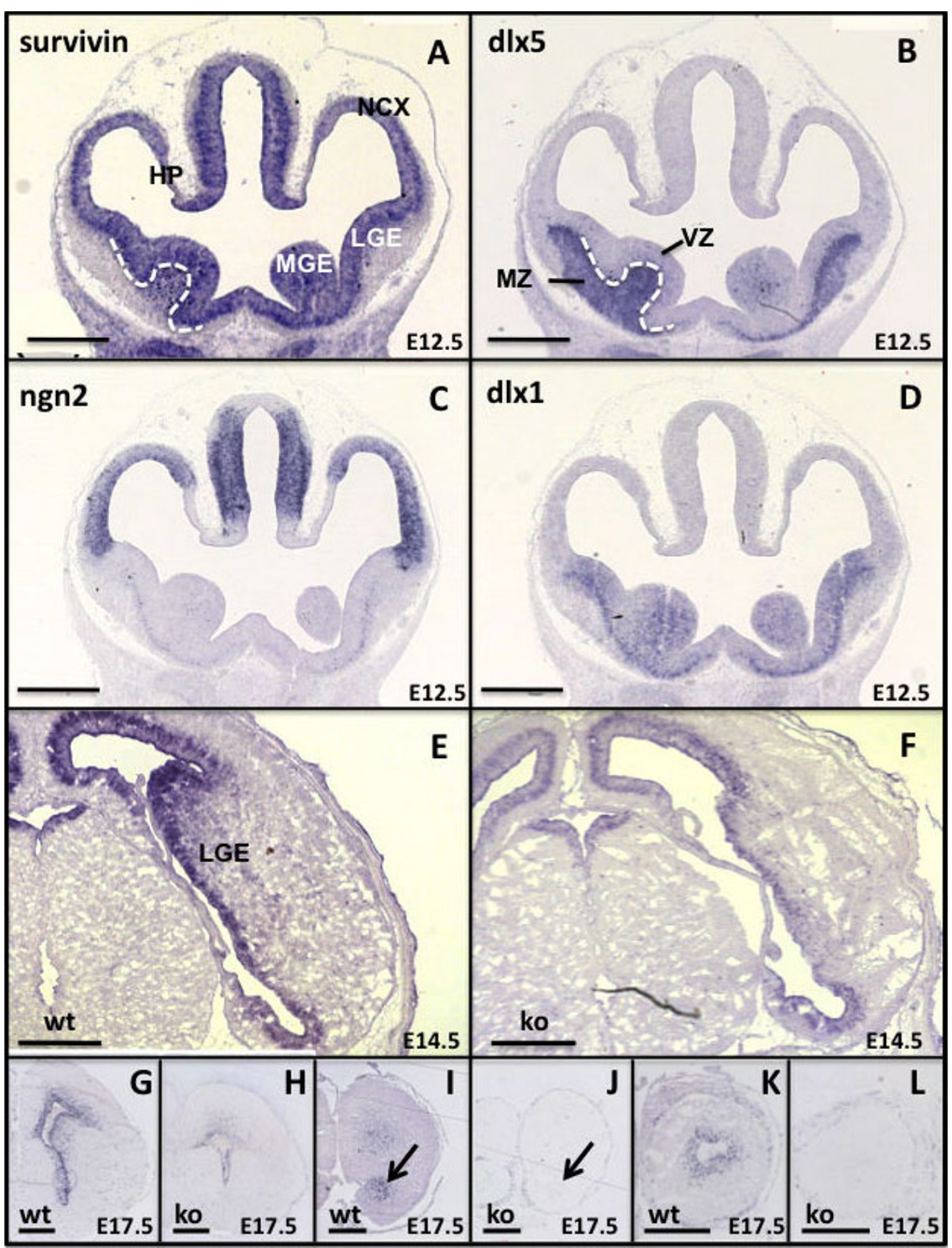

Figure 1 Expression of survivin mRNA in developing mouse brain. In situ hybridizations were performed on coronal brain sections from control (wt) (A-D, G, l, K) and Survivin Camcre ( $k o)(H, J, L)$ embryos, and on transverse brain sections from control (E) and Survivin ${ }^{\text {Camcre }}(F)$ embryos. (A-D) mRNA expression of survivin (A), dlx5 (B), ngn2 (C), and dlx1 (D) on adjacent brain sections from control mice illustrates overlap of survivin expression with $\mathrm{dl} \times 1$ and $\mathrm{ngn2}$. Dashed white line (A, B) indicates minimal overlap of survivin with dlx5. (E-L) Expression of survivin mRNA is reduced in the medial and lateral ganglionic eminences (MGE, LGE) $(F, H)$, the RMS (arrow, J), and the OB $(L)$ in Survivin ${ }^{\text {Camcre embryos }}$ as compared to controls. NCX, neocortex; HP, hippocampus. Scale bars: $500 \mu \mathrm{m}$ 


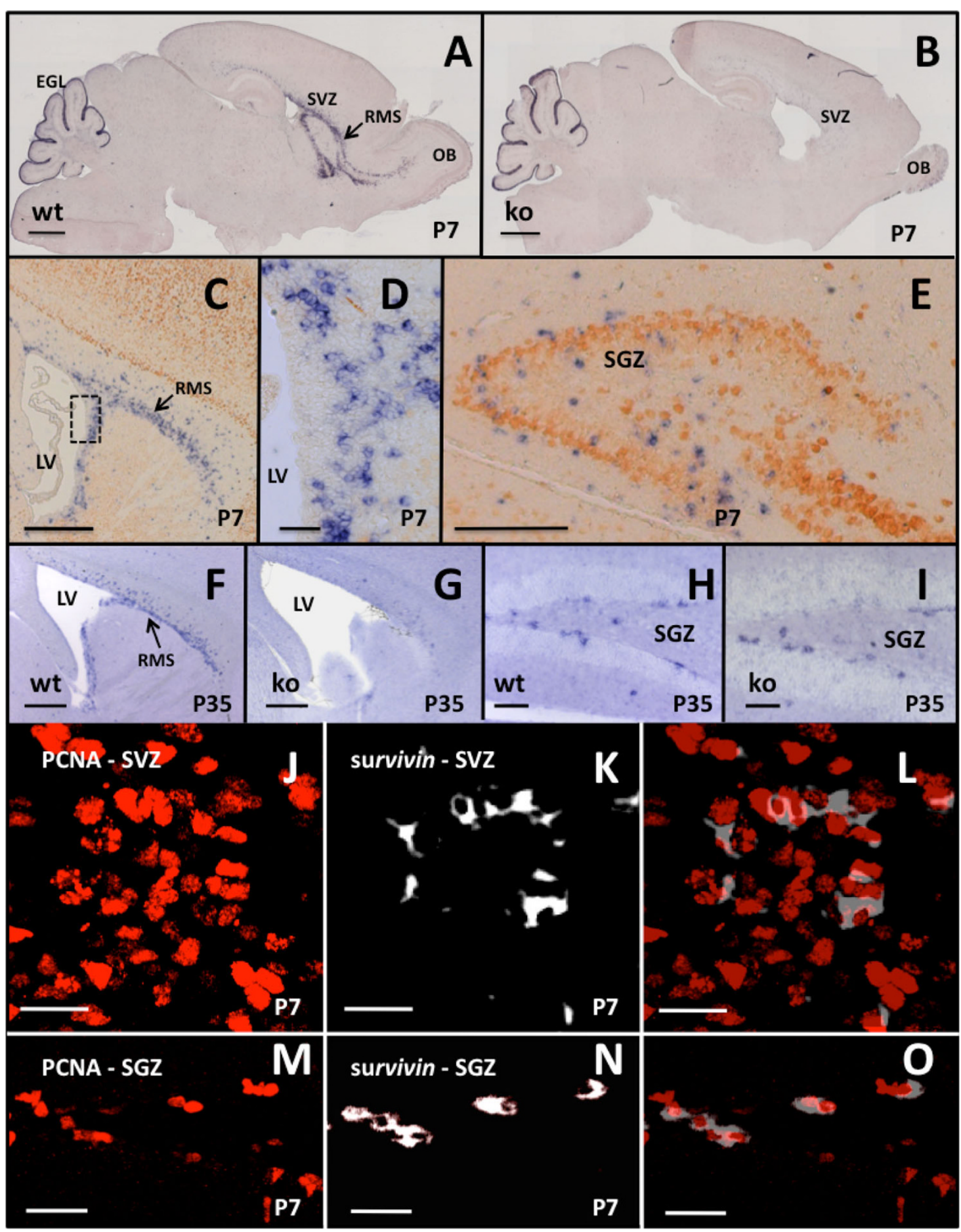

Figure 2 Postnatal expression of survivin mRNA in neural precursor cells. Sagittal sections of brains were used to examine expression of survivin. (A, B) At P7, Survivin mRNA was detected in the DG, SVZ, RMS, OB, and EGL of controls (A), and absent in the SVZ and RMS, but not in the DG and EGL of Survivin Camcre mouse brains (B). (C-E) Double labeling to detect survivin mRNA (blue) and NeuN protein (orange) expression in the SVZ-RMS (C, D) and the DG (E) in P7 control brains, shows that survivin is not expressed in NeuN+ cells. D is a magnified view of the dashed box in C. (F-I) Survivin mRNA expression at P35 is restricted to neural precursor cells in the SVZ, RMS and SGZ in control mice (F, H).

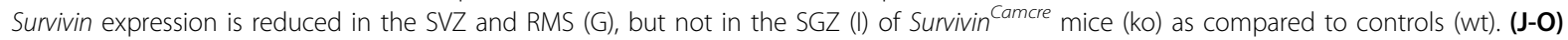
Sagittal sections of control P7 brains through the SVZ (J-L) and through the SGZ (M-O) were stained for PCNA (red nuclei) $(J, M)$ and survivin mRNA (white cytoplasm) $(K, N)$ and the confocal images were overlaid $(L, O)$. Only a subpopulation of PCNA+ cells express survivin. EGL, external germinal layer; OB, olfactory bulb; LV, lateral ventricle. Scale bars: A, B $1000 \mu \mathrm{m}$; C, F, G $500 \mu \mathrm{m}$; D $50 \mu \mathrm{m}$; E $200 \mu \mathrm{m}$; H, I $100 \mu \mathrm{m}$, J-O $20 \mu \mathrm{m}$. 
hypothalamus and amygdala [30]. Postnatal cre expression was absent in NPCs in the SVZ and SGZ (Additional file 1: Supplemental Figure S2). Thus, crossbreeding with the Survivin ${ }^{\text {lox/lox }}$ mice resulted in deletion of both survivin alleles in the neurogenic regions in the prenatal period (ganglionic eminences and neocortex).

\section{Neurogenesis defects in Survivin ${ }^{\text {Camcre embryos }}$}

Cre excision of survivin was assessed by in situ hybridization in Survivin Camcre and corresponding control Survivin ${ }^{l o x / l o x}$ embryos. At E14.5 and E17.5, survivin expression in the Survivin Camcre embyros was markedly reduced in the ganglionic eminences surrounding the lateral ventricles where mitotically active NPCs normally reside, in the RMS and in the OB (Figure $1 \mathrm{~F}, \mathrm{H}, \mathrm{J}, \mathrm{L}$ ). This was associated with increased tunel staining, most evident in the ganglionic eminences, and minimally in the dorsal telencephalon (Figure 3A-D). BrdU labeling studies revealed decreased NPC proliferation in the SVZ, RMS and OB of E17.5 Survivin Camcre embryos (Figure 3E-J). Thus, lack of NPC survivin results in increased embryonic NPC death and decreased NPC proliferation in specific embryonic neurogenic regions.

Altered postnatal neurogenesis in Survivin ${ }^{\text {Camcre }}$ mice Body weights of Survivin ${ }^{\text {Camcre }}$ and control mice were not significantly different at birth. However, during the first month after birth, Survivin ${ }^{\text {Camcre }}$ mice had a significantly higher mortality rate of $28 \%(n=27 / 95)$ compared to $0 \%(\mathrm{n}=0 / 97)$ in control mice. Adult Survivin ${ }^{\text {Camcre }}$ mice also had significantly smaller brains, and the OBs were strikingly hypoplastic (Figure 4A, B) (for brains: $421 \pm 11$ gm versus $329 \pm 7$ gm, for controls versus Survivin Camcre, respectively, $\mathrm{p}<0.001$; for OBs: 19.7 \pm 0.9 gm versus $3.5 \pm 0.2$ gm for controls versus Survivin Camcre, $\mathrm{p}<0.001 ; \mathrm{n}=6$ mice per group). In situ hybridization confirmed loss of survivin expression in the SVZ and RMS (Figure 2A, B, F, G). Surprisingly, expression of survivin in the SGZ was not decreased postnatally in Survivin Camcre mice (Figure 2I). Nissl stained brain sections from Survivin ${ }^{\text {Camcre }}$ mice revealed loss of the RMS, decreased cortical thickness (average reduction to $80 \%$ of control at bregma levels $-1.34 /$ $1.70 /-2.46 /-2.80 \mathrm{~mm} ; \mathrm{n}=4$ mice per group, $\mathrm{p}<0.01$ at each bregma level), enlarged ventricles, yet no morphological changes in the hippocampus (Figure $4 \mathrm{C}, \mathrm{D}$ ). The latter was confirmed by quantifying the volumes corresponding to the GCL and the hilus of the DG (GCL: $0.11 \pm 0.01 \mathrm{~mm}^{3}$ versus $0.12 \pm 0.01 \mathrm{~mm}^{3}$ for control and Survivin ${ }^{\text {Camcre }}$ mice, respectively; hilus: $0.11 \pm 0.01$ $\mathrm{mm}^{3}$ versus $0.15 \pm 0.02 \mathrm{~mm}^{3}$ for control and SurvivinCamcre mice, respectively; $\mathrm{n}=4-5$ mice per group, $\mathrm{p}>$ 0.05).

The hypoplastic OB and absent RMS, in concert with reduced expression of NPC survivin in the SurvivinCamcre mice might be caused by decreased NPC proliferation, increased cell death, and/or deficits in

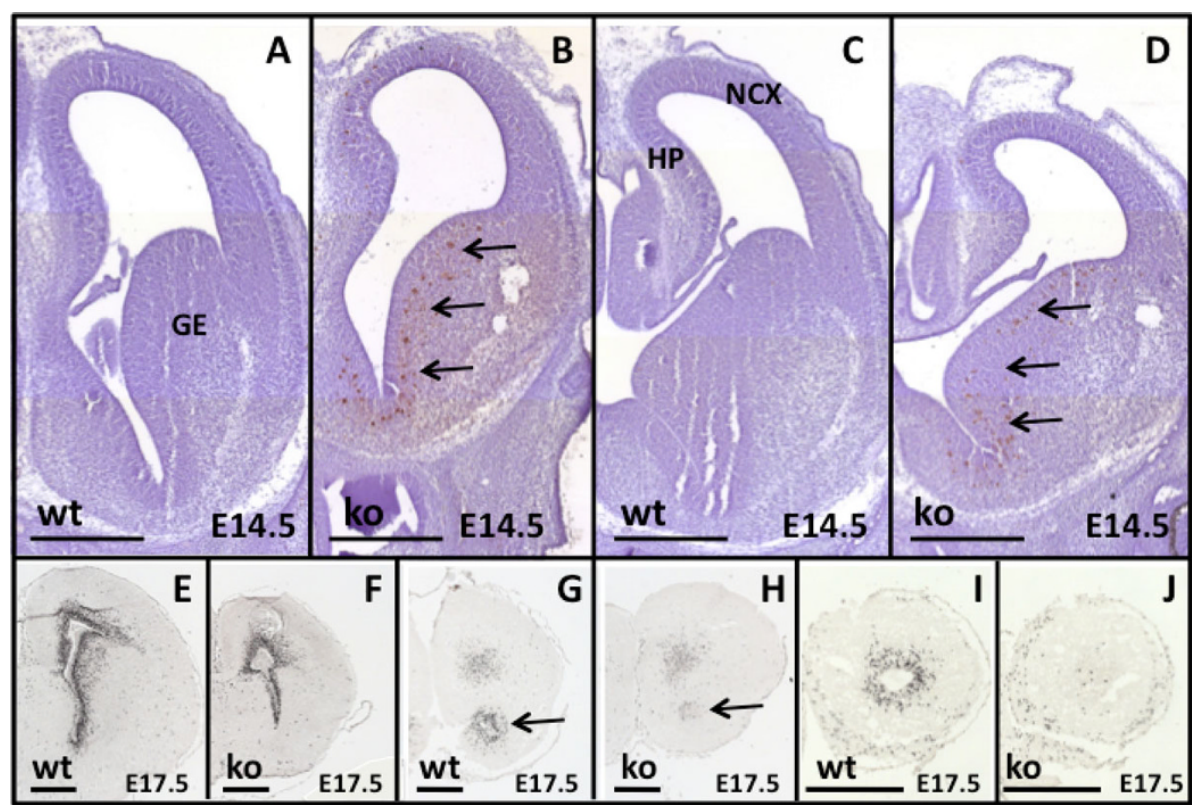

Figure 3 Neurogenesis defects in Survivin ${ }^{\text {Camcre }}$ embryos. (A-D) Tunel labeling of coronal sections of E14.5 brains illustrates increased

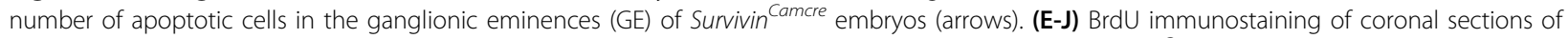

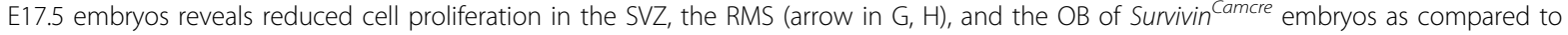
controls. NCX, neocortex; HP, hippocampus. Scale bars: $500 \mu \mathrm{m}$ 


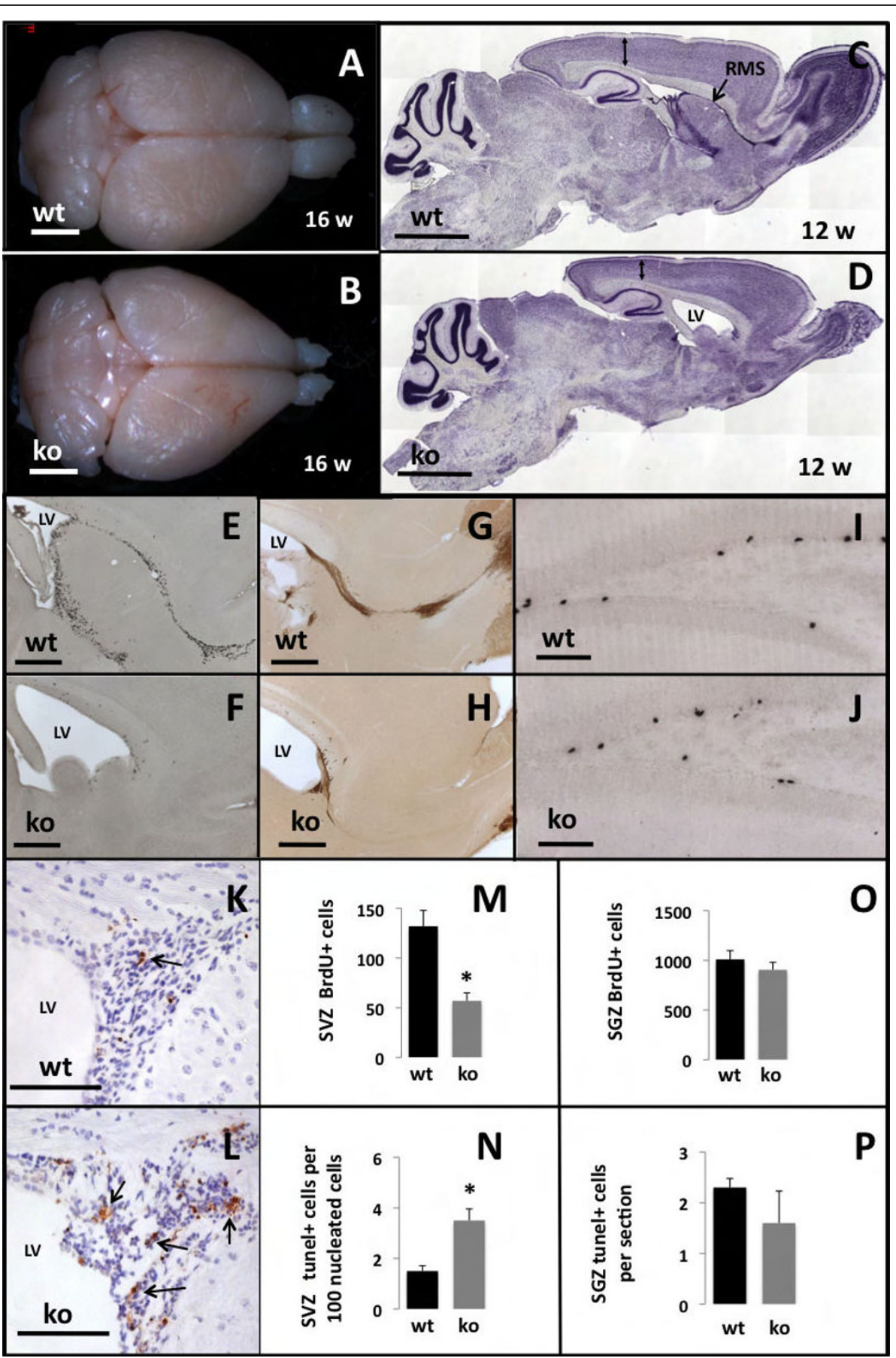

Figure 4 Altered neurogenesis in adult Survivin ${ }^{\text {Camcre }}$ mice. (A, B) Dorsal view of control (wt) and Survivin ${ }^{\text {Camcre }}$ (ko) whole brains at 16

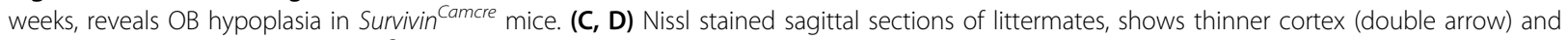
absence of the RMS in the Survivin ${ }^{\text {Camcre }}$ mice. $(\mathbf{E}, \mathbf{F}, \mathbf{I}, \mathbf{J})$ BrdU labeling of sagittal sections of brains from 12 week old mice shows proliferation in the SVZ-RMS pathway (E, F) and in the SGZ (I, J), that is reduced only in the SVZ of Survivin camcre mice (F) as compared with controls (E). (G, H) DCX immunostaining of sagittal sections through the forebrain of control $(G)$ and Survivin ${ }^{\text {Camcre }}(H)$ mice. (M, O) Quantification of BrdU ${ }^{+}$cells in the SVZ (M) and the SGZ (O) was performed as detailed in Methods. There was a significant reduction in BrdU+ cells in the SVZ, but not in the SGZ of Survivin ${ }^{\text {Camcre }}$ mice as compared to controls. $(\mathbf{K}, \mathbf{L})$ Coronal sections through the anterior SVZ of control $(\mathrm{K})$ and Survivin ${ }^{\text {Camcre }}(\mathrm{L})$ mice were stained for tunel+ apoptotic cells (arrows). (N, P) The number of tunel+ cells in the SVZ (N) and the SGZ (P) of control and Survivin ${ }^{\text {Camcre }}$ mice was quantified as described in Methods. There was a significant increase in tunel+ cells in the SVZ but not in the SGZ of Survivin ${ }^{\text {Camcre }}$ mice as compared to controls. LV, lateral ventricle. Results in panels $\mathrm{M}, \mathrm{N}, \mathrm{O}, \mathrm{P}$ are reflected as means $+\mathrm{SEM}, \mathrm{n}=4-5$ mice per group. ${ }^{*} \mathrm{P}<$

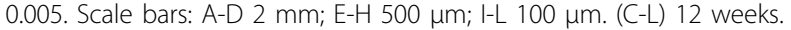


migration. Accumulation of cells in the anterior SVZ of the Survivin ${ }^{\text {Camcre }}$ mice was not observed, mitigating against a predominant migration defect. NPC proliferation, assessed $1 \mathrm{hr}$ after a single dose of BrdU, revealed a significant reduction in BrdU labeled cells in the SVZ of the Survivin ${ }^{\text {Camcre }}$ mice $(132 \pm 16$ cells versus $57 \pm 8$ cells for control and Survivin Camcre mice, respectively, $\mathrm{n}$ $=4-5$ mice per group, $\mathrm{p}=0.002$ ) (Figure 4E, F, M). Furthermore, both BrdU and DCX labeled cells were almost completely absent in the RMS, in striking contrast to the controls (Figure 4E-H). Cell death in the SVZ of the Survivin Camcre mice was also significantly increased (Figure $4 \mathrm{~K}, \mathrm{~L}, \mathrm{~N}$ ), as quantified by the number of tunel+ cells in the anterior SVZ $(1.5+0.21 / 100$ nucleated cells versus $3.5+0.46$ tunel + cells $/ 100$ nucleated cells, for control and Survivin Camcre mice, respectively, $\mathrm{n}=4-5$ mice per group, $\mathrm{p}=0.004$ ) (Figure $4 \mathrm{~N})$. In the RMS and OB, there were some tunel+ cells identified in the brains of the control mice, but not in Survivin Camcre mice, the latter likely due to the lack of precursor cells in this region.

As noted above, survivin expression in the SGZ of the DG was not appreciably diminished after cre excision. There was also no alteration in the number of proliferating or immature neurons in the SGZ, as quantified by BrdU labeling $(1010+88$ versus $905+75$ cells in controls and Survivin ${ }^{\text {Camcre }}$ mice, respectively, $\mathrm{n}=4-5$ mice per group, $\mathrm{p}=0.39$ ) (Figure 4I, J, O) or DCX immunoreactivity (not shown). Nor could we detect changes in tunel+ staining $(2.3+0.18$ versus $1.6+0.63$ tunel+ cells/section in controls and Survivin ${ }^{\text {Camcre }}$ mice, respectively, $\mathrm{n}=3-4$ mice per group, $\mathrm{p}=0.30$ ) (Figure 4P).

In summary, striking survivin-dependent defects in neurogenesis are evident postnatally in the RMS and OB of Survivin Camcre mice, due to a combination of increased SVZ NPC apoptosis and diminished cellular proliferation. Despite the fetal abnormalities, and in striking contrast to the RMS-OB, there were no obvious structural defects or alterations in hippocampal neurogenesis in the Survivin ${ }^{\text {Camcre }}$ mice that had no appreciable reduction in survivin expression within the hippocampus.

Embryonic survivin administration increases neurogenesis In pilot studies, we assessed whether prenatal administration of survivin to increase expression in NPCs could promote neurogenesis. E12.5 control Survivin ${ }^{\text {lox/lox }}$ and Survivin ${ }^{\text {Camcre }}$ embryos received an intracerebroventricular injection in utero with the lentiviral vector pCHMWS-eGFP-T2A-SRV140 (survivin vector) or pCHMWS-eGFP-T2A-Fluc (control vector). At P21, immunohistochemical analysis of the control Survivin ${ }^{l o x /}$ lox mice that received the survivin vector revealed an increased number of embryonic precursor cell-derived cells in the $\mathrm{OB}$ as compared with the control vector
(Additional file 1: Supplemental Figures S3A, B). With Survivin Camcre embryos, the survivin vector did not apparently reverse the $\mathrm{OB}$ hypoplasia when examined at P21, but there were notably more embryonic precursor cell-derived cells in the OB of 3 out of 3 Survivin ${ }^{\text {Camcre }}$ mice that received the survivin vector, as compared with the 2 Survivin ${ }^{\text {Camcre }}$ mice that received the control vector (Additional file 1: Supplemental Figures S3C, D). Overall, these preliminary findings suggest that enhanced expression of NPC survivin may increase neurogenesis.

\section{Survivin ${ }^{\text {Camcre }}$ mice have a thinner cortex with fewer} GABAergic interneurons and a lower seizure threshold Although the average cortical thickness in the SurvivinCamcre mice was reduced, in situ hybridization with cortical markers (Cux2 for layers 2-4 [33], Badlamp for layers 2/3/5 [34], and ER81 for layer 5 [35] confirmed the correct orientation and presence of all the cortical layers (not shown). Moreover, and in line with limited expression of cre recombinase in the dorsal telencephalon of CamKII $\alpha$-cre embryos, the density of cortical vGLUT1+ glutamatergic cells in the Survivin Camcre mice was not altered $\left(2282+157\right.$ cells $/ \mathrm{mm}^{2}$ versus $2480+71$ cells $/ \mathrm{mm}^{2}$ in controls and Survivin Camcre mice, respectivley, $\mathrm{n}=4-5$ mice per group, $\mathrm{p}=0.30$ ) (Figure 5A-C). In contrast, and consistent with prominent apoptosis and diminished BrdU labeling in the ganglionic eminences, prenatal depletion of survivin in the NPCs of Survivin ${ }^{\text {Camcre }}$ mice resulted in a significant reduction in the density of GAD65/67+ GABAergic interneurons in the postnatal adult cortex $\left(493+12\right.$ cells $/ \mathrm{mm}^{2}$ versus $417+6$ cells $/ \mathrm{mm}^{2}$ in controls and Survivin Camcre mice, respectively, $\mathrm{n}=5-6$ mice per group, $\mathrm{p}<0.001$ ) (Figure $5 \mathrm{D}-\mathrm{F})$. This occurred in the absence of any changes in interneurons in the hippocampus (hilus + granular cell layer: $213 \pm 8$ cells $/ \mathrm{mm}^{2}$ versus $209 \pm 17$ cells $/ \mathrm{mm}^{2}$ in controls and Survivin ${ }^{\text {Camcre }}$ mice, respectively, $\mathrm{n}=4$ mice per group, $\mathrm{p}=0.82$ ). These data indicate an alteration in the excitatory/inhibitory balance in the brain of Survivin Camcre mice that might be associated with postnatal alterations in cognition and behavior, and a lower seizure threshold.

Indeed, during routine handling, $2.5 \%(\mathrm{n}=9 / 352)$ of the Survivin ${ }^{\text {Camcre }}$ mice were recorded to have spontaneous tonic-clonic, generalized motor seizures starting from 2 weeks of age (no seizures observed in controls). To investigate seizure susceptibility, the response of control and Survivin Camcre mice to kainic acid (KA) was assessed over a period of 2 hours. Control, saline-treated animals ( $\mathrm{n}=9$ per group) showed no signs of epileptic activity. However, in response to KA, Survivin Camcre mice exhibited a lower threshold for seizures that were more severe. Thus, at a subconvulsive dose of $20 \mathrm{mg} / \mathrm{kg}$, KA induced limbic motor convulsions in $15 \%(n=2 / 13)$ 


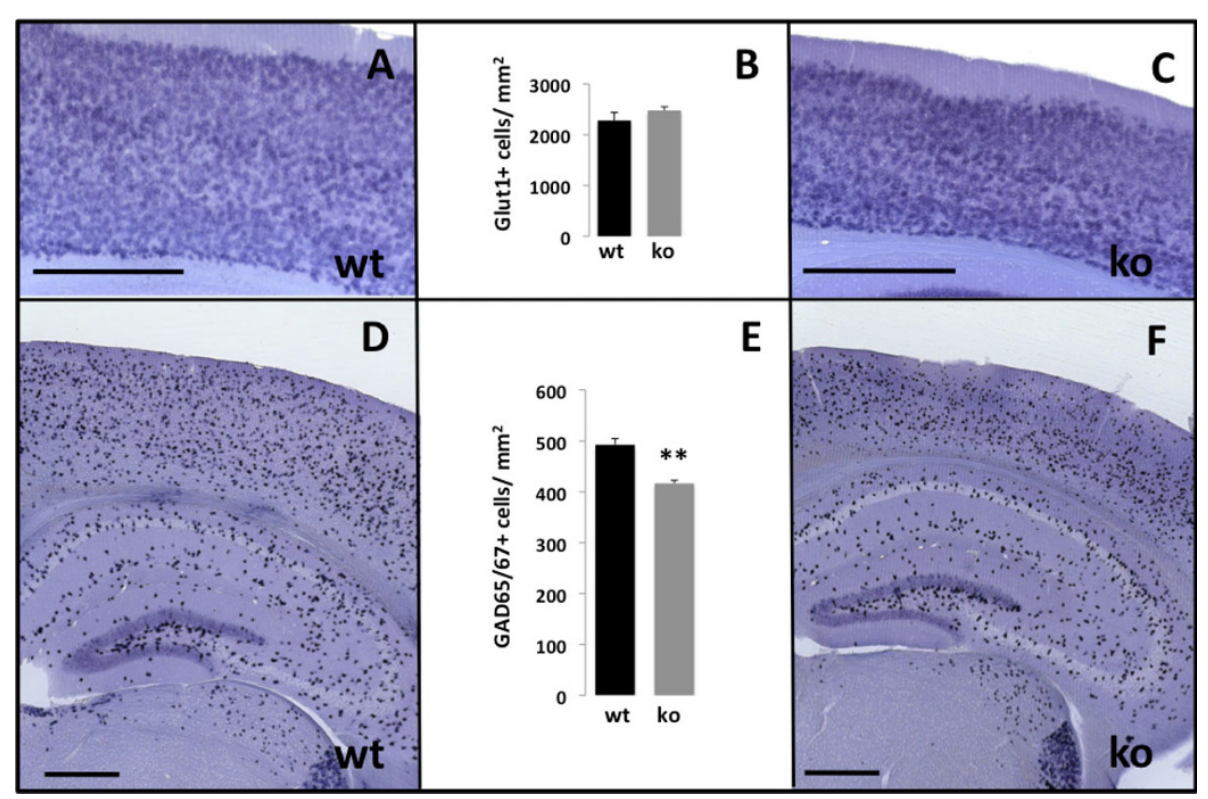

Figure 5 GABAergic and glutamatergic inter/neurons. In situ hybridizations of coronal sections were performed to detect and quantify VGLUT1+ glutamatergic neurons (A-C) and GAD65/67+ GABAergic interneurons (D-F) in adult littermates. (A-C) In spite of Survivin Camcre mice having a thinner cortex, the density of VGLUT1+ cells in the cortex was not signficantly different between Survivin ${ }^{\text {camcre }}$ and control mice. (D-F)

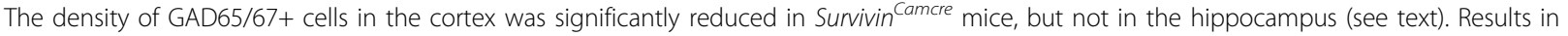
panels $B$ and $E$ are reflected as means + SEM, $n=4-6$ mice per group. ${ }^{*} \mathrm{P}<0.001$ Scale bars: $500 \mu \mathrm{m}$.

of control mice and $81 \%(\mathrm{n}=13 / 16)$ Survivin ${ }^{\text {Camcre }}$ mice (Figure 6A). The maximum seizure score was significantly higher in the Survivin ${ }^{\text {Camcre }}$ mice $(\mathrm{p}<0.001)$. Seizure severity over the $2 \mathrm{hr}$ observation period was also significantly greater in the Survivin Camcre mice $(\mathrm{p}<$ 0.001 ) (Figure 6B). At a KA dose of $30 \mathrm{mg} / \mathrm{kg}$, the mean latency to the first seizure was also shorter in the Survivin ${ }^{\text {Camcre }}$ mice compared to control mice $(8.75 \pm 2.75$ versus $30 \pm 7.64 \mathrm{~min}$, respectively, $\mathrm{n}=4$ mice per group, $\mathrm{p}=0.031$ ). At that dose, all Survivin ${ }^{\text {Camcre }}$ mice rapidly developed status epilepticus (stage 5-6) and died of severe generalized convulsions, while all control animals survived the KA treatment (Figure 6A). Thus, Survivin $^{\text {Camcre }}$ mice exhibit enhanced susceptibility to KA seizures.

Neuropeptide Y (NPY) is a multifunctional peptide that is expressed in GABAergic interneurons, regulates pre-synaptic excitatory transmission in the DG, and has anti-epileptic properties [36]. Hilar NPY interneuron degeneration, ectopic expression of NPY in mossy fibers, and axonal sprouting are common features of limbic hyperexcitability [37]. Due to the increased seizure activity in the Survivin Camcre mice, we examined NPY expression under both basal conditions (saline treatment) and following induction of seizures (KA $20 \mathrm{mg} / \mathrm{kg}$ i.p.). The number of hilar NPY+ interneurons was not different between saline-treated control and Survivin ${ }^{\text {Camcre }}$ mice $\left(490 \pm 17\right.$ versus $398 \pm 53$ cells $/ \mathrm{mm}^{2}$, for control and
Survivin Camcre mice, respectively; $\mathrm{n}=4-5$ mice per group, $\mathrm{p}=0.11$ ). However, two weeks after $20 \mathrm{mg} / \mathrm{kg}$ KA treatment, there were significantly fewer NPY+ cells in the hilus of the Survivin Camcre mice $(446 \pm 22$ versus $306 \pm 65$ cells $/ \mathrm{mm}^{2}$ for control and Survivin ${ }^{\text {Camcre }}$ mice, respectively; $\mathrm{n}=6-9$ mice per group, $\mathrm{p}=0.032$ ). Moreover, ectopic NPY expression in mossy fibers was readily detected in 3 out of 4 saline-treated Survivin ${ }^{\text {Camcre }}$ mice but not in any of the corresponding controls $(n=5)$ (Figure 6C, D). This effect became more prominent after KA (5/6 Survivin ${ }^{\text {Camcre }}$ mice as compared to 0/9 controls). In 2 of these Survivin ${ }^{\text {Camcre }}$ mice, we furthermore observed ectopic NPY immunoreactivity in the supragranular layer, likely reflecting sprouting of mossy fibers (not shown).

Since seizure activity modulates hippocampal neurogenesis, we also evaluated the seizure-induced neurogenic response of the control and Survivin Camcre mice. The volumes of the GCL and the hilus were not different between control and Survivin Camcre mice (see above), and KA had no effect on that relationship (data not shown). To assess cell proliferation, BrdU was injected 3 days after KA or saline injection, and mice were sacrificed 1 day later. After saline injection, the total number of SGZ BrdU+ cells was not different in control and Survivin ${ }^{\text {Camcre }}$ mice $(648 \pm 58$ cells versus $705 \pm 99$ cells in controls and Survivin Camcre mice, respectively, $\mathrm{n}=4$ mice per group, $\mathrm{p}=0.64$ ) (Figure 


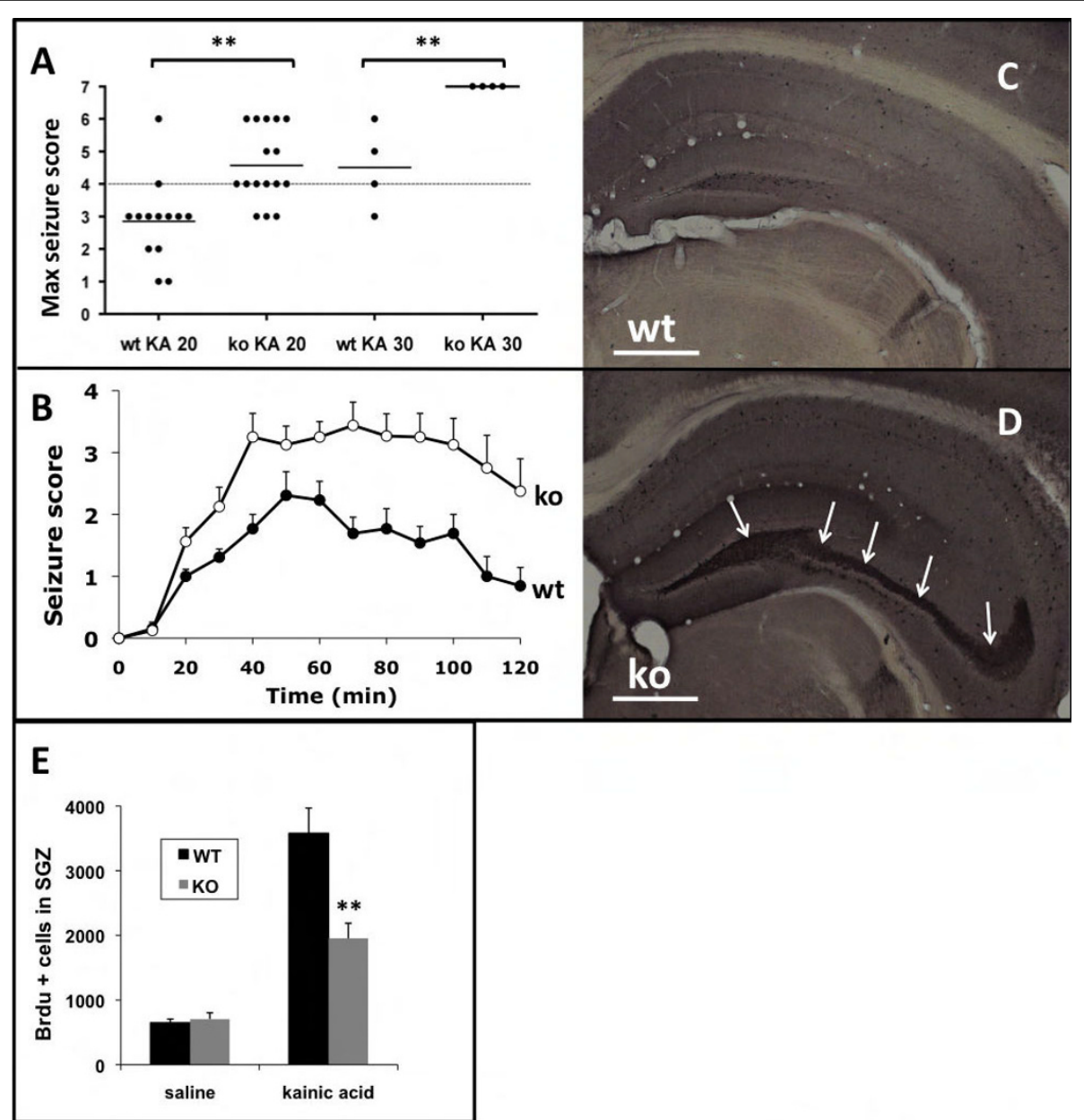

Figure 6 Survivin ${ }^{\text {Camcre }}$ mice exhibit increased seizure activity. (A) Scatter plot showing the maximum seizure score assigned to each experimental animal during a $2 \mathrm{hr}$ observation period following KA administration. Seizure scores were significantly higher in the Survivin ${ }^{\text {camcre }}$ mice as compared to controls. Horizontal bars indicate the mean for each group. (B) KA (20 mg/kg ip) induced signficantly more severe seizure activity in Survivin ${ }^{\text {Camcre }}$ mice as compared to controls, $\mathrm{P}<0.001, \mathrm{n}=13-16$ mice per group. (C, D) Representative NPY-stained coronal sections

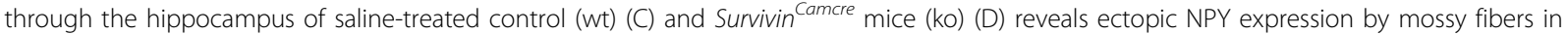

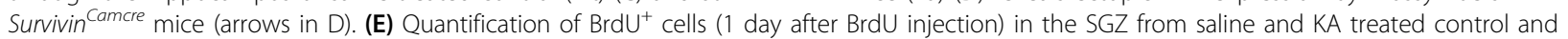
Survivin ${ }^{\text {Camcre }}$ mice. The neurogenic response to KA was significantly dampened in Survivin ${ }^{\text {Camcre }}$ mice as compared to controls, $\mathrm{n}=4-5$ mice per group. Results in panels B and E are reflected as means + SEM. ${ }^{* *} \mathrm{P}<0.001$. Scale bars: C-D $500 \mu \mathrm{m}$.

6E). Compared to saline treated controls, KA treated mice exhibited an increase in the number of BrdU+ cells in the SGZ after KA injection. However, the neurogenic response was significantly dampened in the Survi$v_{i n}{ }^{\text {Camcre }}$ KA treated mice compared to control KA treated mice $(3578 \pm 392$ cells versus $1955 \pm 233$ cells for controls and Survivin Camcre mice, respectively, $\mathrm{n}=5$ mice per group, $\mathrm{p}<0.001$ ) (Figure 6E). Numbers of BrdU+ cells remained reduced 2 weeks following KA in the Survivin ${ }^{\text {Camcre }}$ mice as compared to controls (data not shown). Thus, despite the higher seizure scores following KA in the Survivin ${ }^{\text {Camcre }}$ mice, there was less seizure-induced neurogenesis in the Survivin ${ }^{\text {Camcre }}$ versus the control mice.
Survivin ${ }^{\text {Camcre }}$ mice exhibit learning and memory defects Adult Survivin ${ }^{\text {Camcre }}$ mice exhibited several defects that may contribute to disorders in behavior and cognition, including reduced SVZ-RMS-OB neurogenesis $[38,39]$, OB hypoplasia [40], diminution of cortical GABAergic neurons, and seizures. We therefore evaluated the effects of depleting NPCs of survivin by subjecting the Survivin ${ }^{\text {Camcre }}$ and matched controls to a range of behavioral studies.

There was no difference in body weight between the Survivin ${ }^{\text {Camcre }}$ and control mice at the start of behavioral testing $(21.6 \pm 0.6 \mathrm{gm}$ versus $20.1 \pm 0.6 \mathrm{gm}$ for the Survivin ${ }^{\text {Camcre }}$ and controls, respectively, $\mathrm{p}=0.081$ ), and the Survivin Camcre mice had normal visual and 
auditory skills, grip strength, rotarod performance, pain response and cage activity (Additional file 1: Supplemental Figures S4, S5; Additional file 2: Supplemental Methods and Results).

In the open field test, the Survivin Camcre mice displayed significant disturbances in exploratory behavior, including delayed first entry to the center, fewer center entries, more corner crossings, and less time in the center (Figure 7A). This type of behavioral outcome is often suggestive of increased anxiety, however the Survivin ${ }^{\text {Camcre }}$ mice performed normally in the elevated plus maze test for anxiety. On the maze, there was no difference between control and Survivin Camcre mice in the total number of beam crossings $(148 \pm 5$ versus $155 \pm 9$ for control and Survivin ${ }^{\text {Camcre }}$ mice respectively; $\mathrm{n}=12$ mice per group, $\mathrm{p}=0.48)$, percent time spent in the open arms (33 \pm 2 versus $36 \pm 4$ for control and Survivin $^{\text {Camcre }}$ mice respectively; $\mathrm{n}=12, \mathrm{p}=0.76$ ), nor percentage of entries into the open arms (26 \pm 2 versus 23 \pm 3 for control and Survivin ${ }^{\text {Camcre }}$ mice respectively; $\mathrm{n}=$ $12, \mathrm{p}=0.07)$. The findings suggest that the poor performance of the Survivin ${ }^{\text {Camcre }}$ mice in the open field test may not be due to increased anxiety, but rather due to a distinct defect in exploratory behavior.

The Survivin ${ }^{\text {Camcre }}$ mice exhibited a significant impairment in passive avoidance learning. During the initial training trial, there was no difference in step-through latencies $\left(12.5 \pm 4.5\right.$ versus $13.9 \pm 1.8 \mathrm{sec}$, Survivin ${ }^{\text {Camcre }}$ and control mice respectively, $\mathrm{p}=0.783$ ). However, during testing, the Survivin ${ }^{\text {Camcre }}$ mice demonstrated significantly shorter latency to enter the dark compartment than the controls $(235 \pm 27$ versus $71 \pm 24$ sec for control and Survivin ${ }^{\text {Camcre }}$ mice, $\mathrm{n}=12, \mathrm{p}<0.001$ ) (Additional file 1: Supplemental Figure S6), consistent with poor associative memory of aversive stimuli.

We examined auditory and contextual fear memory using an auditory cue as the conditioned stimulus (CS), and a foot shock as an aversive stimulus. Freezing times in baseline, pre-US, post-US, and pre-CS trials were not different between the groups (Figure 7B). However, Survivin ${ }^{\text {Camcre }}$ mice exhibited significantly less freezing response in the context and auditory cue (CS) trials compared to control mice (context: $25.7 \pm 5.5$ versus $68.2 \pm 4.5$; auditory: $34.3 \pm 9.0$ and $84.4 \pm 7.8$, respectively for Survivin ${ }^{\text {Camcre }}$ and control mice, $\mathrm{n}=12$ mice per group, $\mathrm{p}<0.001$ ) (Figure 7B).

Lastly, we assessed hippocampus-dependent spatial learning and long-term memory in the Survivin Camcre mice using the Morris water maze. Swimming velocity was not different between the controls and the SurvivinCamcre mice, excluding defects in motor ability. During acquisition training, the Survivin ${ }^{\text {Camcre }}$ mice showed training-dependent reduction in escape latency and path length. However, the improvements were minimal as compared with controls, and the escape latency and path length were significantly increased in the SurvivinCamcre mice ( $\mathrm{p}<0.001, \mathrm{n}=12$; by two way repeated measures ANOVA) (Figure 8A, B). Notably, lengths of the escape paths were not different between the Survivin Camcre mice and control mice during 4 visible-platform training days $(803+88 \mathrm{~cm}$ versus $1076+110 \mathrm{~cm}$ for control, $\mathrm{n}=10$, and Survivin Camcre mice, $\mathrm{n}=12$, respectively; $\mathrm{p}=0.075)$. These results indicate that the Survivin Camcre mice were fully capable and motivated to choose the shortest pathway towards the platform in the cued, non-spatial condition of the task.

In the first probe trial performed after 5 days of training, the control mice already had a preference for the target quadrant compared to adjacent $1(\mathrm{p}=0.002)$ and opposite ( $\mathrm{p}=0.02)$ quadrants, whereas the SurvivinCamcre mice had no preference at all $(\mathrm{p}=0.46)$ (Figure $8 \mathrm{C})$. In the second probe trial after 10 days of training, the control mice continued to show a strong preference for the target quadrant compared to all other quadrants ( $\mathrm{p}<0.001$ ), whereas the Survivin Camcre mice equally favoured the target and adjacent 2 quadrants $(\mathrm{p}=0.60)$ versus the other 2 quadrants $(\mathrm{p}<0.05)$ (Figure $8 \mathrm{D}, \mathrm{E})$. Since the Morris water maze test is a stress that might alter neural cell proliferation, we also quantified the number of Ki67+ cells in the dentate gyrus of the Survivin ${ }^{\text {Camcre }}$ mice $(\mathrm{n}=4)$ and the corresponding littermate controls $(n=4)$ after the probe trials. There was no significant difference in the number of Ki67+ cells between the two groups $(534+49$ cells versus $480+28$ cells in controls versus Survivin ${ }^{\text {Camcre }}$ mice, respectively, $\mathrm{p}=$ 0.378).

Overall, the Survivin Camcre mice exhibited exploratory behavioral abnormalities, with global deficits in various forms of learning and memory.

\section{Discussion}

In this report, we show that survivin is prominently expressed in the neurogenic regions of the embryonic mouse brain, and that its expression by a subpopulation of NPCs is maintained postnatally in the two key sites of adult neurogenesis - the SVZ and the SGZ. Lack of expression of survivin in the NPCs during embryonic development, was associated with profound SVZ-RMSOB postnatal defects in neurogenesis and loss of interneurons, manifest by major deficits in learning and memory, and heightened sensitivity to seizures. Prenatal administration of survivin in the brain enhanced neurogenesis in the SVZ-RMS-olfactory system. Our findings position survivin as a central player in regulating neurogenesis during embryonic development, alterations of which impact on postnatal brain function.

The embryonic forebrain, the telencephalon, consists of two parts. The dorsal aspect is the origin of 


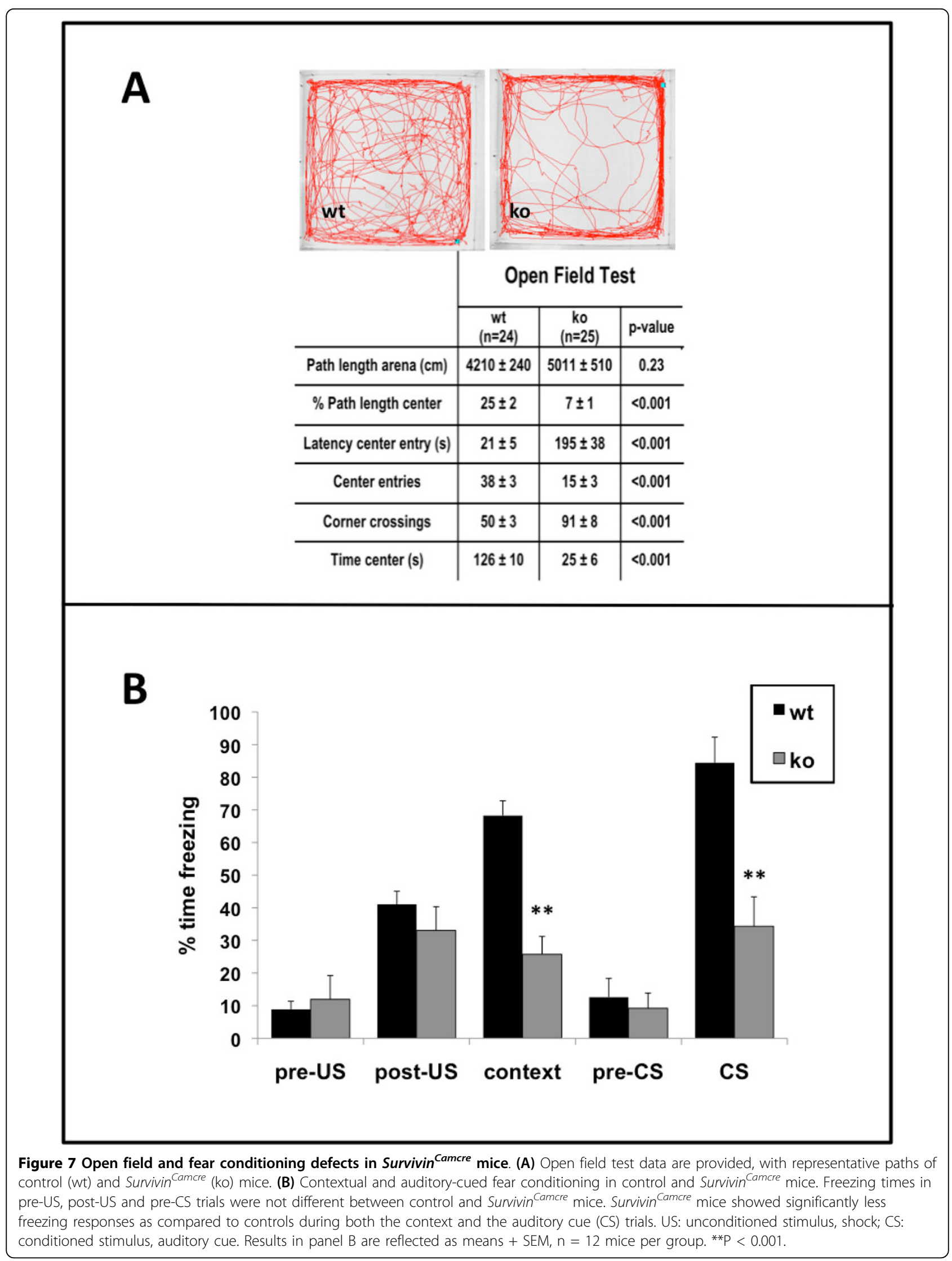




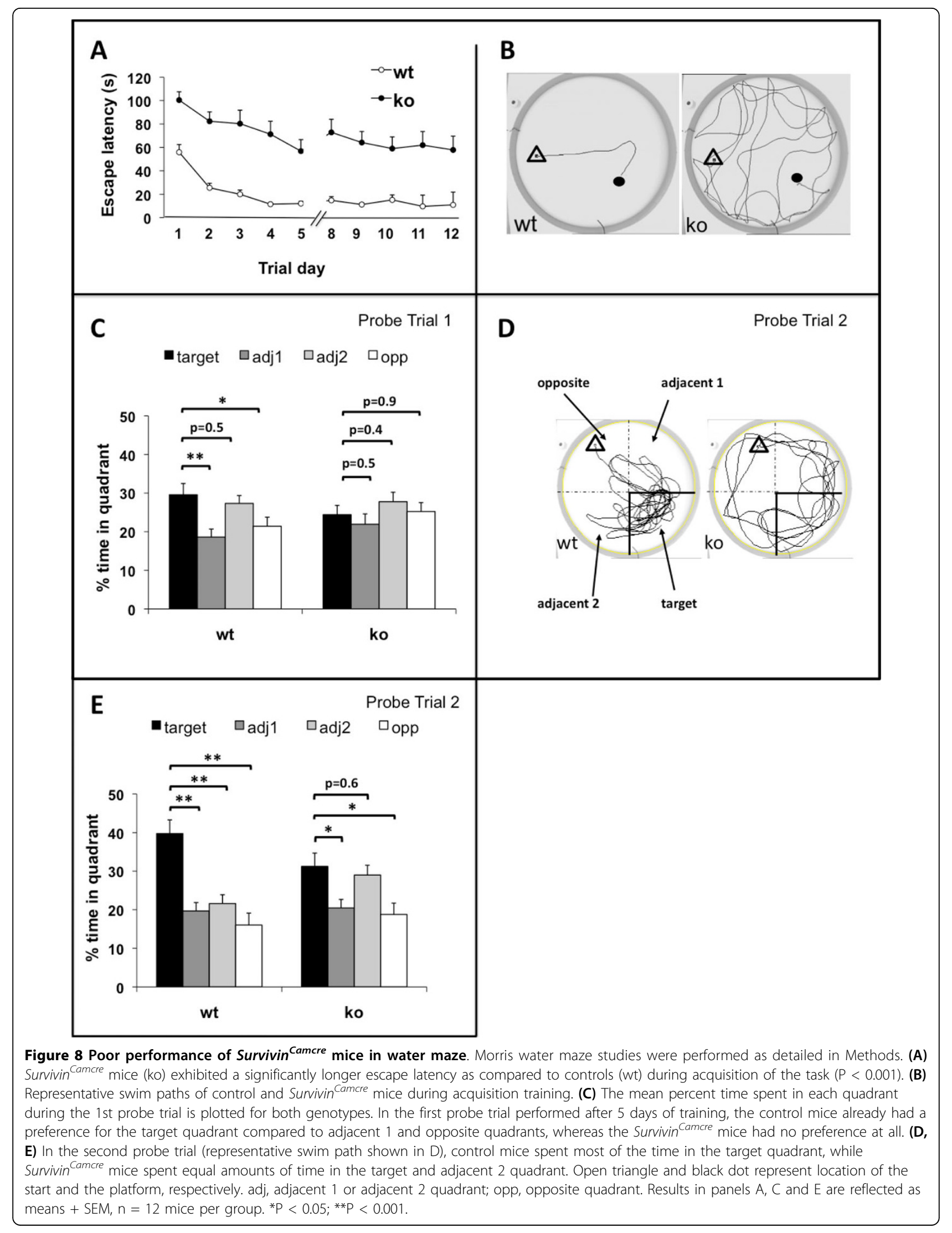


glutamatergic excitatory neurons of the cerebral cortex and hippocampus [41]. The ventral part, comprising the ganglionic eminences, gives rise to the basal ganglia. The LGE provides neurons for the striatum [42], interneurons of the olfactory bulb (OB) [43], and most adult SVZ NPCs [2]. The MGE is the source of most neocortical [42] and hippocampal interneurons [44], as well as striatal interneurons. At E12.5, survivin is widely expressed in the neurogenic region of the ventral and dorsal telencephalon. Since cre recombinase expression in the CamKII $\alpha$-cre mice is low in the dorsal telencephalon, generation of principal glutamatergic neurons was largely unaffected in the adult, and the overall integrity of the hippocampus and cortex was maintained, albeit the latter was thinner. In contrast, the number of cortical GABAergic neurons, which arise primarily in the ganglionic eminences and comprise 25$30 \%$ of cortical neurons, was significantly reduced in the Survivin Camcre mice. This reduction may have been further contributed to by the paucity of SVZ NPCs, recently shown to be a continuous postnatal source of GABAergic interneurons in the cortex [45].

Imbalances in inhibitory and excitatory circuits due to decreases in numbers of interneurons, are well known to be associated with seizures in humans and experimental animal models $[46,47]$. This was clearly evident in the Survivin Camcre mice which, even under naïve conditions, displayed spontaneous, generalized tonic-clonic motor seizures, a phenotype that was more dramatically revealed following challenge with KA. Indeed, SurvivinCamcre mice showed a rapid and consistent generalization of seizures at KA doses that normally result in focal hippocampal epileptic activity [48]. Thus, a defect in the cortical inhibitory system may explain the higher susceptibility to generalized convulsions in the SurvivinCamcre mice.

Our studies demonstrate that the loss of a subpopulation of NPCs in the SVZ of neonatal and adult SurvivinCamcre mice, with resultant near-absence of the RMS and $\mathrm{OB}$, was due to a combination of increased apoptosis and decreased cellular proliferation of NPCs in the corresponding embryonic neurogenic region (ganglionic eminences). Indeed, this is in line with the fact that survivin is a pro-survival molecule with the capacity to inhibit apoptosis and to promote the cell cycle and mitosis (reviewed in [49]). Somewhat surprisingly, in spite of profound disturbances in neurogenesis in the SVZ, we did not detect baseline changes in neurogenesis in the SGZ of the DG in the Survivin Camcre mice, or significant loss of survivin expressing DG NPCs. Although this may be due to cre recombinase inefficiency, the finding may also be due to the embryonic origin of SGZ NPCs being different from the SVZ NPCs, which still remains to be clarified [50]. There is however, a defect in SGZ neurogenesis in the Survivin ${ }^{\text {Camcre }}$ mice that is only evident under stress conditions. This may mean that the baseline source(s) of SGZ NPCs is different from that recruited during stress, an hypothesis that requires testing. In the Survivin ${ }^{\text {Camcre }}$ mice, the neurogenic response was significantly impaired as compared to the controls after KA-induced seizures. Alterations in GABA signaling in the Survivin Camcre mice may be implicated [51], but other factors that are important in maintaining the function of the neurogenic niche in the hippocampus could also contribute to the dampened response [52]. Further study to identify those that are relevant is ongoing.

Although the integrity of the hippocampus was apparently maintained under baseline conditions, upon testing, the Survivin ${ }^{\text {Camcre }}$ mice exhibited striking defects in memory and cognition, that are consistent with hippocampal dysfunction. In fact, the behavioral abnormalities were associated with a significant impairment of longterm potentiation (LTP) in the CA1 region of the hippocampus (not shown), a finding that frequently is associated with poor memory, and often with increased epileptic activity. As with the seizure disorder, a loss of cortical inhibitory interneurons likely contributed to the behavioral abnormalities and cognitive defects in the Survivin ${ }^{\text {Camcre }}$ mice. We also cannot exclude a contribution of suboptimal neurogenic responses to the behavioral phenotype, as neurogenic defects in both the SGZ and SVZ have been implicated in memory, cognition, mood, and hippocampal-dependent learning [53]. Moreover, olfactory bulbectomy in rodents impairs neurogenesis in both the SGZ and the SVZ, disrupts normal hippocampal LTP, and causes significant deficits in learning and memory. Thus, the $\mathrm{OB}$, which sends projections to the hippocampus [54], also plays a role in normal behavior and cognition $[12,13,40]$. Indeed, since the Survivin ${ }^{\text {Camcre }}$ mice have major defects in neurogenesis, as well as notable hypoplasia of the OB, all of which are associated with epileptic activity and major alterations in behavior, it is reasonable to consider that the effective lack of an OB exacerbates the loss of SVZ and possibly SGZ NPCs, which in turn, contributes to the behavioral abnormalities and enhanced seizure activity.

\section{Conclusions}

We have established that prenatal expression of survivin in neurogenic regions of the developing brain plays a key role in learning and memory and in determining seizure susceptibility. Prenatal stresses are recognized to suppress postnatal neurogenesis that in turn, induces behavioral abnormalities in the neonate and adult $[8,9]$. While the underlying molecular mechanisms have not been delineated, it is reasonable to consider that 
alterations in embryonic NPC survivin expression might contribute to those phenotypic changes. Pilot data indicate that prenatal administration of survivin can enhance neurogenesis in the olfactory system. We do not yet know whether the resultant new neurons differentiate or integrate, or whether the SGZ is also affected. Nonetheless, the findings are promising, supporting the critical nature of this molecule, and its potential as a therapeutic target. Our mouse model provides the opportunity to elucidate the relevance of survivinexpressing NPC subpopulations in vivo in response to a range of environmental stresses, and genetic or epigenetic factors.

\section{Methods}

\section{Transgenic mice and genotyping}

Mice that express Cre recombinase driven by the promoter of the gene for calmodulin-dependent protein kinase II $\alpha$ (CamKII $\alpha$ ) [30,31] (gift of Dr. G. Schütz, Heidelberg, Germany) were bred with mice in which the survivin gene is flanked by loxP sites [32]. The resulting offspring that were heterozygous for Cre and homozygous for floxed survivin (Survivin ${ }^{\text {lox/lox }}$ ) (hereafter referred to as Survivin ${ }^{\text {Camcre }}$ mice) were compared to littermate control mice which did not express Cre and were Survivin $^{\text {lox/lox }}$. Survivin ${ }^{\text {lox/lox }}$ embryos and adults were not different from Survivin ${ }^{l o x / w t}$, Survivin ${ }^{w t / w t}$ or CamKII $\alpha$-cre:survivin ${ }^{l o x / w t}$ mice. Mice were maintained on a C57B/6:Swiss:129svj 75:12.5:12.5 background. Genotyping of tail DNA was performed by PCR as previously reported [30,32]. Mice were group-housed in standard mouse cages in a room with a $12 \mathrm{~h}$ light-dark cycle and ad libitum access to food and water and all animal experiments were approved by the ethics committee of the University of Leuven.

\section{BrdU labeling and quantification}

Adult mice and pregnant females were injected intraperitoneally (ip) with 5-bromo-2-deoxyuridine (BrdU, Sigma Aldrich, Bornem, Belgium) at a concentration of $50 \mathrm{mg}$ per $\mathrm{kg}$ body weight. For the analysis of the embryos, 1 hour after injection of BrdU, pregnant females were killed by cervical dislocation, after which the embryos were harvested, placed in ice-cold PBS, and then fixed in $4 \%$ paraformaldehyde (Para) for cutting 20 $\mu \mathrm{m}$ cryo sections using a microtome/cryostat (HM550, Microm, Walldorf, Germany). For analysis of adults, mice were anesthetized with sodium pentobarbital at 1 hour (unless stated otherwise) after BrdU and perfused transcardially with $0.9 \% \mathrm{NaCl}$, followed by fixation with $4 \%$ paraformaldehyde. Brains were dissected and postfixed overnight at $4^{\circ} \mathrm{C}$ and $40 \mu \mathrm{m}$ tissue sections were prepared using a vibrating microtome (HM650V, Microm, Walldorf, Germany).
The number of BrdU+ cells in the adult dentate gyrus (DG) was quantified using a modified version of the optical fractionator method [55] with Stereo Investigator software (MicroBrightField, Colchester, VT, USA). Cells were counted with a $40 \times$ objective on every sixth section through the entire rostrocaudal extension of one half of the DG, restricted to the subgranular zone (SGZ) [56]. The number of BrdU+ cells in the SVZ of one lateral ventricle was counted with a $40 \times$ objective on 1 coronal section (bregma level $+0.14 \mathrm{~mm}$ ) per animal.

\section{Immunohistochemistry}

Immunostaining protocols were optimized for the different tissue preparations and antibodies. In general, tissue sections were treated with $1 \% \mathrm{H}_{2} \mathrm{O}_{2}$ in $\mathrm{PBS} /$ methanol for $15 \mathrm{~min}$, incubated in $5 \%$ serum for $30 \mathrm{~min}$, and incubated overnight at $4^{\circ} \mathrm{C}$ in following primary antibodies: rabbit anti-neuropeptide Y (NPY) antibody (1:5000, Bachem, UK); mouse anti-NeuN (1:500, Chemicon, Hofheim, Germany); mouse anti-PCNA (1:1000, Chemicon, Hofheim, Germany); rabbit anti-DCX (1:500, Cell Signaling, MA, USA); rat anti-BrdU (1:500, Immunologicals Direct, Oxford, UK); chicken anti-GFP (1:3000, Aves, Oregon, USA); and rabbit anti-Cre recombinase (1:3000, gift from Dr. Schütz, Heidelberg, Germany); rabbit antiKi67 (1:1000 Monosan, Uden, The Netherlands). After washes, the corresponding biotinylated secondary antibody was added for 1 hour and the signal was amplified using the Vectastain Elite ABC kit (Vector Laboratories, CA, USA). Peroxidase activity was detected with 3,3'diaminobenzidine (DAB peroxidase substrate tablet set, Sigma Aldrich, Bornem, Belgium). For fluorescent staining, Alexa-conjugated secondary antibodies (Molecular Probes, Leiden, The Netherlands) were used. BrdU staining was performed as reported previously [57].

\section{In situ hybridization}

Digoxygenin (DIG)-labeled RNA probes for Dlx1 [58], Dlx5 [24], Ngn2 (gift from Dr. A. Simeone), GAD65 [59], GAD67AE [60] and vGLUT1 (Allen Institute for Brain Science) were generated using the DIG RNA Labeling Kit (Roche Diagnostics, Basel, Switzerland), according to the manufacturer's instructions. GAD65 and GAD67AE probes were mixed to detect the total number of GABAergic interneurons. For survivin riboprobes, full-length murine survivin cDNA was cloned into the pcDNA3 plasmid vector (Invitrogen, CA, USA) [61], and linearized for generation of antisense and sense probes using Sp6 RNA polymerase or T7 polymerase, respectively. In situ hybridization and combined immunohistochemistry protocols were adapted from those reported [33,62] and completed on $20 \mu \mathrm{m}$ cryostat or $40 \mu \mathrm{m}$ vibratome sections. 


\section{Measurement of granular cell layer (GCL) volume and hilar volume}

Coronal sections through the DG were stained with cresyl violet. Pictures were taken at $4 \times$ magnification, and the area of the GCL and the hilus was determined off line using Metamorph software (Molecular Devices, Sunnyvale, CA). Volumes were calculated and expressed in $\mathrm{mm}^{3}$.

\section{Quantification of apoptosis (tunel+ cells)}

Detection of cellular apoptosis in $10 \mu \mathrm{m}$ coronal paraffin sections, prepared using a HM360 microtome (Microm, Walldorf, Germany), was accomplished using the ApopTag Peroxidase In Situ Apoptosis Detection Kit (Chemicon, Hofheim, Germany). The number of tunel+ cells was counted with a $40 \times$ objective. The anterior subventricular zone (SVZa) was analyzed at level bregma +0.98 $\mathrm{mm}$ and the data are presented as the number of tunel+ cells per 100 nucleated cells. The subgranular zone (SGZ) was analyzed at bregma levels -1.34/-1.70/-2.46/$2.80 \mathrm{~mm}$ and the data are presented as the number of tunel+ cells per section.

\section{Quantification of inhibitory and excitatory neurons}

Numbers of neurons and interneurons were quantified hemilaterally on coronal vibratome sections at 4 bregma levels (-1.34/-1.70/-2.46/-2.8 mm). GAD65/67+ cells were counted with a $10 \times$ objective in the hilus plus the granule cell layer, and in the parieto/temporal cortex, in a $1.4 \mathrm{~mm}$ wide band from the white matter to the pial surface. vGLUT1+ cells in the parieto/temporal cortex were counted with a $20 \times$ objective in a $0.7 \mathrm{~mm}$ wide band. NPY + cells in the hilus were counted with a $20 \times$ objective on every sixth section ( $40 \mu \mathrm{m}$ thick). Results are presented as the number of cells per $\mathrm{mm}^{2}$.

\section{Quantification of Ki67 positive cells}

Ki67 positive cells in the SGZ were counted hemilaterally with a $40 \times$ objective on every third $40 \mu \mathrm{m}$ section between bregma levels -1.34 and $-2.8 \mathrm{~mm}$. The number of counted cells was multiplied by 3 to obtain the total number of Ki67 positive cells.

\section{Intracerebroventricular (ICV) injection of lentiviral vector in embryos}

Lentiviral vectors were prepared, encoding enhanced green fluorescent protein (eGFP) and survivin separated by a T2A sequence starting from pCHMWS-eGFP-T2AFluc (gift from Dr. V. Baekelandt, KULeuven). The Fluc fragment was removed from pCHMWS-eGFP-T2A-Fluc using BamHI and $M l u \mathrm{I}$ and replaced by the cDNA encoding full-length murine survivin. Survivin expression from this vector was confirmed by Western blot analysis of lysates from transfected COS cells. Human immunodeficiency virus type 1 (HIV-1)-derived lentiviral vectors were produced by a standard protocol. The viral vector was mixed with Fast Green dye $(0.005 \%$ final concentration, Sigma-Aldrich, Bornem, Belgium), which allowed visualization of the distribution of the viral vector in the cerebral ventricles after injection. Pregnant mice (stage E12.5) were anesthetized with $50 \mathrm{mg} / \mathrm{ml}$ ketamine, $2 \%$ xylazine in saline and placed supine on a heating pad. A 2-cm midline incision was made through the skin and the abdominal wall. The uterine horn was drawn out through the hole onto gauze, and with the uterus transilluminated, a 35 gauge needle (beveled NanoFil needle, World Precision Instruments, FL, USA) was inserted into the ventricle, and $1 \mu \mathrm{l}$ viral vector solution was injected at a speed of 406 nanoliters per second using a Mycro4 MicroSyringe Pump Controller (World Precision Instruments, FL, USA).

\section{Seizure studies}

Seizures in adult male mice were evoked by ip administration of kainic acid (KA) (Sigma, MO, USA). KA was dissolved in saline and injected at 20 or $30 \mathrm{mg} / \mathrm{kg}$ body weight. Saline-injected animals were used as controls. Seizure severity was quantified by an observer blind to the mouse genotype using the following scale $[48,63]$ : stage 0 , normal behavior; stage 1 , immobility; stage 2 , forelimb and/or tail extension, rigid posture; stage 3, repetitive movements, head bobbing; stage 4 , rearing and falling; stage 5, continuous rearing and falling; stage 6 , severe whole-body convulsions; and stage 7 , death. For each animal, seizure severity was scored every 10 min over a period of 2 hours after KA administration. The maximum score reached by each animal over the entire observation period was used to calculate the maximum seizure score for each treatment group. Seizure severity over the 2 hour observation period was calculated for each mouse as the area under the seizure score versus time curve (AUC), and the average AUC was calculated for each treatment group.

\section{Behavioral studies}

Behavioral tests were initiated when the mice were 3-4 months of age, $\mathrm{n}=12-25$ per group. Neuromotor, exploration, and learning tests were performed in the following sequence: cage activity, grip strength, rotarod, open field, elevated plus maze, Morris water maze, passive avoidance. Contextual fear conditioning was performed on a separate group of mice. Animals were tested during the light phase of the light-dark cycle. All studies were performed by observers who were blinded to the genotype of the mice.

Open field exploratory activity was assessed in a 50 $\mathrm{cm} \times 50 \mathrm{~cm}$ arena using EthoVision video tracking and software (Noldus, Wageningen, The Netherlands). Mice were individually placed in a specific corner of the open field, and were allowed a $1 \mathrm{~min}$ adaptation period. The path was recorded for $10 \mathrm{~min}$ to measure dwells and entries in different parts of the field. Measures included total path length, percentage path length in the center circle (diameter $30 \mathrm{~cm}$ ), entries into the four corner 
squares, entries into the center, time spent in the center versus periphery, latency of first center approach, and frequency of rearing.

The elevated plus maze $[64,65]$, to evaluate anxietylike behavior, had two open arms $(21 \mathrm{~cm} \times 5 \mathrm{~cm})$ and two closed arms of the same size, with high side walls, and was raised $30 \mathrm{~cm}$ above the table. Each mouse was placed in the central square of the maze, facing one of the closed arms. After $1 \mathrm{~min}$, exploratory behavior was recorded automatically during a $10 \mathrm{~min}$ period using five infrared beams, connected to an activity logger. For each mouse, the number of arm entries, percentage of open arm entries, and percentage time spent in the open arms was assessed.

Passive avoidance (aversive) learning [66] was tested in a two-compartment step-through box. Animals were adapted to the dark for $30 \mathrm{~min}$, and then placed into a small illuminated compartment. After $5 \mathrm{~s}$, a sliding door leading to the large dark compartment was opened. Upon entry, the door was closed and the animal received an electric foot shock $(0.3 \mathrm{~mA}, 1 \mathrm{~s})$. Twentyfour hours later, the animals were placed again in the light compartment and the latency to enter the dark compartment was measured up to $300 \mathrm{~s}$, to evaluate memory of the foot shock.

Contextual and auditory-cued fear conditioning $[67,68]$ was tested in a Plexiglas chamber with a grid floor through which a foot shock could be administered. Mice were trained and tested on 3 consecutive days: On the day 1 , the mice were individually placed in the testing chamber and allowed to adapt for $5 \mathrm{~min}$. On the day 2 , the animals were allowed to explore the testing chamber for $2 \mathrm{~min}$, after which an auditory cue (conditioned stimulus, CS) was presented for $28 \mathrm{~s}$, followed by a foot shock (0.3 mA, $2 \mathrm{~s}$; unconditioned stimulus, US). The time (\%) spent freezing during the first $2 \mathrm{~min}$ and $28 \mathrm{~s}$ is the pre-US score. The mice were then allowed to explore again for $1 \mathrm{~min}$, and the auditory cue and shock were again presented, followed by another $2 \mathrm{~min}$ exploration (post-US score). On day 3 (24 hours after training), mice were returned to the same context in which training occurred, and freezing behavior was recorded for 5 min (context test). Ninety min later, freezing was recorded in a novel environment (the grid floor was hidden and a scent of peppermint was added) for $3 \mathrm{~min}$ without the auditory cue stimulus (pre-CS test). Finally, the auditory cue was turned on, and the time spent freezing was recorded over the following 3 min (cue CS test).

Spatial learning and memory were examined in a Morris water maze $[69,70]$, which consisted of a circular tank $(32.5 \mathrm{~cm}$ high $\times 150 \mathrm{~cm}$ diameter $)$, filled with water (up to $16 \mathrm{~cm}$ deep), maintained at $26^{\circ} \mathrm{C}$, and made opaque with nontoxic white paint. A circular platform $(15 \mathrm{~cm}$ high $\times 15 \mathrm{~cm}$ diameter $)$ remained hidden $1 \mathrm{~cm}$ below the water surface at a fixed position. The room housing the tank had a permanent display of distal extra-maze cues. The swim paths of the mice were recorded using computerized EthoVision video tracking equipment. During training (acquisition phase), the mice were given four swim trials daily with an intertrial interval of $15 \mathrm{~min}$. The mice were placed in the pool facing the wall at one of four starting positions. If the animal did not find the platform after $120 \mathrm{~s}$, it was guided there by the experimenter. Mice were allowed to rest $15 \mathrm{~s}$ on the platform before being removed from the pool. Latency to reach the platform, path length, and average swim speed were recorded. After five training days, there were two days of rest, followed by another five days of training and two days of rest. Probe trials were performed on days 8 and 15. During probe trials, the platform was removed and each animal was monitored once for $100 \mathrm{~s}$, recording the percentage time in each quadrant. Over all the trials, one SurvivinCamcre mouse floated with a speed of $<5 \mathrm{~cm} / \mathrm{s}$, and this mouse was therefore excluded from the study.

\section{Statistical analyses}

Data are presented as the mean \pm SEM. Data were analyzed with a two tailed t-test, Mann-Whitney Rank Sum Test, one way ANOVA, or two way repeated measures ANOVA. All statistical tests were performed at a significance level of 0.05 .

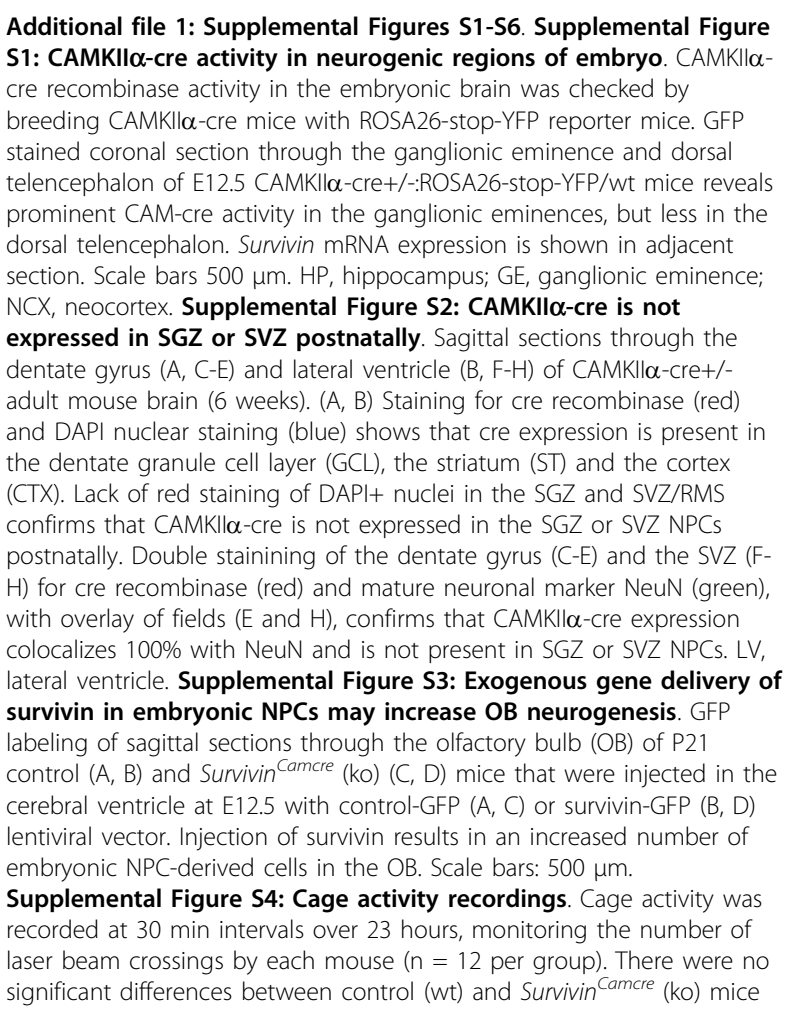

Additional file 1: Supplemental Figures S1-S6. Supplemental Figure S1: CAMKIl $\alpha$-cre activity in neurogenic regions of embryo. CAMKIl $\alpha$ telencephalon of E125 CAMK\|l $\alpha$-cre+/-ROSA26-stop-YFP/wt mice reveals prominent CAM-cre activity in the ganglionic eminences, but less in the orsal telencephalon. Survivin mRNA expression is shown in adjacent onic eminence; dentate gyrus (A, C-E) and lateral ventricle (B, F-H) of CAMKIll $\alpha$-cre+t(a) the dentate granule cell layer (GCL), the striatum (ST) and the cortex (CTX). Lack of red staining of DAPI+ nuclei in the SGZ and SVZ/RMS $\mathrm{H})$ for cre recombinase (red) and mature neuronal marker NeuN (green), with overlay of fields ( $E$ and $H$ ), confirms that CAMKIl $\alpha$-cre expression survivin in embryonic NPCs may increase OB neurogenesis. GFP labeling of sagittal sections through the olfactory bulb (OB) of P21 cerebral ventricle at $E 125$ with control-GFP $(A, C)$ or survivin-GFP $(B, D)$ lentiviral vector. Injection of survivin results in an increased number of recorded at 30 min intervals over 23 hours, monitoring the number of significant differences between control (wt) and Survivin ${ }^{\text {Camcre }}$ (ko) mice 
in the total number of beam crossings $(p=0.40)$ and no alterations in circadian activity profiles $(p=0.30)$. Results reflect means + SEM.

Supplemental Figure S5: Visual evoked potentials. Visual evoked

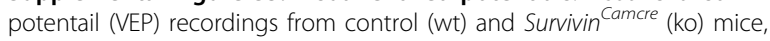
reveal similar peak latency and amplitude for both genotypes.

Supplemental Figure S6: Passive avoidance studies. The Survivin ${ }^{\text {Camcre }}$ mice (ko) exhibited a significant impairment in passive avoidance learning, indicated by their shorter latency to enter the dark compartment than the controls (wt).

Click here for file

[http://www.biomedcentral.com/content/supplementary/1471-2202-11-2S1.PPTX ]

Additional file 2: Supplemental Methods and Results. Additional methods and results

Click here for file

[http://www.biomedcentral.com/content/supplementary/1471-2202-11-2S2.rtf ]

\section{Acknowledgements}

This work was supported in part by the Fonds voor Wetenschappelijk Onderzoek (FWO), Belgium. YB was supported by grants from Parents Against Childhood Epilepsy (PACE, Inc.), NY, USA, and the Italian National Research Council (CNR - "Ricerche Spontanee a Tema Libero" - RSTL Program).

\section{Author details}

${ }^{1} \mathrm{KU}$ Leuven, VIB Vesalius Research Center (VRC), Herestraat 49, Gasthuisberg ON1, B3000 Leuven, Belgium. ${ }^{2} \mathrm{KU}$ Leuven Laboratory of Biological Psychology, Tiensestraat 102, B3000 Leuven, Belgium. ${ }^{3}$ Dept of Pharmacology, University of Milan, via Vanvitelli 32, Milan, Italy. ${ }^{4}$ Istituto di Neuroscienze, Consiglio Nazionale delle Ricerche, via G. Moruzzi 1, 56100 Pisa, Italy. ${ }^{5} \mathrm{KU}$ Leuven, Laboratory for Neurobiology and Gene Therapy, Kapucijnenvoer 33, B3000 Leuven, Belgium. ${ }^{6}$ Developmental Biology Institute of Marseille, NMDA CNRS, INSERM, Univ. de Mediterranee, Campus de Luminy, 13288 Marseille, France. ${ }^{7}$ Department of Psychiatry, University of Texas Southwestern Medical Center, 5323 Harry Hines Blvd, Dallas, Texas, 75390-9070 USA. ${ }^{8}$ Department of Cellular and Molecular Medicine Neuroscience Program, University of Ottawa, 451 Smyth Road, Ottawa, K1H 8M5 Canada. ${ }^{9}$ Laboratory of Molecular Neuropathology, Centre for Integrative Biology, University of Trento, via delle Regole 101, 38060 Trento, Italy. ${ }^{10}$ Center for Blood Research, Faculty of Medicine, University of British Columbia, 2350 Health Sciences Mall, Vancouver, V6T 1 Z3 Canada.

\section{Authors' contributions}

$\mathrm{VC}$ was involved in designing and performing all experiments. $\mathrm{VC}, \mathrm{DL}, \mathrm{AE}$ $R D^{\prime} H, U B, M C, V B$ and $H C$ helped in drafting the manuscript. VC, VR, AD, JC, $\mathrm{MM}$ and TJ prepared riboprobes, did CDNA cloning and sequencing, in situ hybridizations, in vivo studies, histologic sectioning, acquisition of data and analyses. TA, DB, RD'H helped in behavioral studies. FA, YB, MC helped in seizure studies. AE and DL provided continuous intellectual input, evaluation and interpretation of data. EC conceived, designed and co-ordinated the project, and drafted the manuscript. All authors read and approved the final manuscript.

Received: 24 July 2009

Accepted: 5 January 2010 Published: 5 January 2010

\section{References}

1. Zhao C, Deng W, Gage FH: Mechanisms and functional implications of adult neurogenesis. Cell 2008, 132:645-660.

2. Young KM, Fogarty M, Kessaris N, Richardson WD: Subventricular zone stem cells are heterogeneous with respect to their embryonic origins and neurogenic fates in the adult olfactory bulb. J Neurosci 2007, 27:8286-8296

3. Luskin MB: Restricted proliferation and migration of postnatally generated neurons derived from the forebrain subventricular zone. Neuron 1993, 11:173-189.
4. Cameron HA, Woolley CS, McEwen BS, Gould E: Differentiation of newly born neurons and glia in the dentate gyrus of the adult rat. Neuroscience 1993, 56:337-344.

5. Arvidsson A, Collin T, Kirik D, Kokaia Z, Lindvall O: Neuronal replacement from endogenous precursors in the adult brain after stroke. Nat Med 2002, 8:963-970.

6. van Praag H, Schinder AF, Christie BR, Toni N, Palmer TD, Gage FH: Functional neurogenesis in the adult hippocampus. Nature 2002, 415:1030-1034.

7. Carlen M, Cassidy RM, Brismar H, Smith GA, Enquist LW, Frisen J: Functional integration of adult-born neurons. Curr Biol 2002, 12:606-608.

8. Lemaire V, Koehl M, Le Moal M, Abrous DN: Prenatal stress produces learning deficits associated with an inhibition of neurogenesis in the hippocampus. Proc Natl Acad Sci USA 2000, 97:11032-11037.

9. Lucassen PJ, Bosch OJ, Jousma E, Kromer SA, Andrew R, Seckl JR, Neumann ID: Prenatal stress reduces postnatal neurogenesis in rats selectively bred for high, but not low, anxiety: possible key role of placental 11 beta-hydroxysteroid dehydrogenase type 2 . The European journal of neuroscience 2009, 29:97-103.

10. Gould E, Beylin A, Tanapat P, Reeves A, Shors TJ: Learning enhances adult neurogenesis in the hippocampal formation. Nat Neurosci 1999, 2:260265.

11. Keilhoff $\mathrm{G}$, Becker A, Grecksch G, Bernstein HG, Wolf G: Cell proliferation is influenced by bulbectomy and normalized by imipramine treatment in a region-specific manner. Neuropsychopharmacology 2006, 31:1165-1176.

12. Hozumi S, Nakagawasai O, Tan-No K, Niijima F, Yamadera F, Murata A, Arai $Y$, Yasuhara $\mathrm{H}$, Tadano T: Characteristics of changes in cholinergic function and impairment of learning and memory-related behavior induced by olfactory bulbectomy. Behavioural brain research 2003, 138:915.

13. Han F, Shioda N, Moriguchi S, Qin ZH, Fukunaga K: The vanadium (IV) compound rescues septo-hippocampal cholinergic neurons from neurodegeneration in olfactory bulbectomized mice. Neuroscience 2008 , 151:671-679.

14. Parent JM: Injury-induced neurogenesis in the adult mammalian brain. Neuroscientist 2003, 9:261-272.

15. Hattiangady B, Shetty AK: Implications of decreased hippocampal neurogenesis in chronic temporal lobe epilepsy. Epilepsia 2008, 49(Suppl 5):26-41.

16. Hagg T: From neurotransmitters to neurotrophic factors to neurogenesis. Neuroscientist 2009, 15:20-27.

17. Trujillo CA, Schwindt TT, Martins AH, Alves JM, Mello LE, Ulrich H: Novel perspectives of neural stem cell differentiation: from neurotransmitters to therapeutics. Cytometry A 2009, 75:38-53.

18. Mattson MP: Glutamate and neurotrophic factors in neuronal plasticity and disease. Annals of the New York Academy of Sciences 2008, 1144:97112.

19. Ihrie RA, Alvarez-Buylla A: Cells in the astroglial lineage are neural stem cells. Cell and tissue research 2008, 331:179-191.

20. Li F, Ling X: Survivin study: an update of "what is the next wave"?. Journal of cellular physiology 2006, 208:476-486.

21. Altieri DC: New wirings in the survivin networks. Oncogene 2008, 27:62766284

22. Adida C, Crotty P, McGrath J, Berrebi D, Diebold J, Altieri D: Developmentally regulated expression of the novel cancer antiapoptosis gene survivin in human and mouse differentiation. Am J Path 1998, 152:43-49

23. Jiang Y, de Bruin A, Caldas H, Fangusaro J, Hayes J, Conway EM, Robinson M, Altura RA: Essential role for survivin in early brain development. J Neurosci 2005, 25:6962-6970.

24. Zerucha T, Stuhmer T, Hatch G, Park BK, Long Q, Yu G, Gambarotta A, Schultz JR, Rubenstein $J$, Ekker M: A highly conserved enhancer in the Dlx5/Dlx6 intergenic region is the site of cross-regulatory interactions between Dlx genes in the embryonic forebrain. J Neurosci 2000, 20:709721.

25. Kele J, Simplicio N, Ferri AL, Mira H, Guillemot F, Arenas E, Ang SL: Neurogenin 2 is required for the development of ventral midbrain dopaminergic neurons. Development 2006, 133:495-505.

26. Panganiban $\mathrm{G}$, Rubenstein JL: Developmental functions of the Distal-less/ Dlx homeobox genes. Development 2002, 129:4371-4386. 
27. Pennartz S, Belvindrah R, Tomiuk S, Zimmer C, Hofmann K, Conradt M, Bosio A, Cremer $\mathrm{H}$ : Purification of neuronal precursors from the adult mouse brain: comprehensive gene expression analysis provides new insights into the control of cell migration, differentiation, and homeostasis. Molecular and cellular neurosciences 2004, 25:692-706.

28. Gleeson JG, Lin PT, Flanagan LA, Walsh CA: Doublecortin is a microtubuleassociated protein and is expressed widely by migrating neurons. Neuron 1999, 23:257-271.

29. Mullen RJ, Buck CR, Smith AM: NeuN, a neuronal specific nuclear protein in vertebrates. Development 1992, 116:201-211.

30. Casanova E, Fehsenfeld S, Mantamadiotis T, Lemberger T, Greiner E, Stewart AF, Schutz G: A CamKIlalpha iCre BAC allows brain-specific gene inactivation. Genesis 2001, 31:37-42.

31. Belz T, Liu HK, Bock D, Takacs A, Vogt M, Wintermantel T, Brandwein C, Gass $P$, Greiner $E$, Schutz G: Inactivation of the gene for the nuclear receptor tailless in the brain preserving its function in the eye. The European journal of neuroscience 2007, 26:2222-2227.

32. Xing Z, Conway EM, Kang C, Winoto A: Essential role of survivin, an inhibitor of apoptosis protein, in T cell development, maturation, and homeostasis. J Exp Med 2004, 199:69-80.

33. Zimmer C, Tiveron MC, Bodmer R, Cremer H: Dynamics of Cux2 expression suggests that an early pool of SVZ precursors is fated to become upper cortical layer neurons. Cereb Cortex 2004, 14:1408-1420.

34. David A, Tiveron MC, Defays A, Beclin C, Camosseto V, Gatti E, Cremer H, Pierre P: BAD-LAMP defines a subset of early endocytic organelles in subpopulations of cortical projection neurons. Journal of cell science 2007, 120:353-365.

35. Lin JH, Saito T, Anderson DJ, Lance-Jones C, Jessell TM, Arber S: Functionally related motor neuron pool and muscle sensory afferent subtypes defined by coordinate ETS gene expression. Cell 1998, 95:393407.

36. Sorensen AT, Nikitidou L, Ledri M, Lin EJ, During MJ, Kanter-Schlifke I, Kokaia M: Hippocampal NPY gene transfer attenuates seizures without affecting epilepsy-induced impairment of LTP. Experimental neurology 2008, 215(2):328-33, 2009.

37. Sperk G, Hamilton T, Colmers WF: Neuropeptide $Y$ in the dentate gyrus. Progress in brain research 2007, 163:285-297.

38. Kempermann G, Brandon EP, Gage FH: Environmental stimulation of 129/ SvJ mice causes increased cell proliferation and neurogenesis in the adult dentate gyrus. Curr Biol 1998, 8:939-942.

39. Snyder JS, Hong NS, McDonald RJ, Wojtowicz JM: A role for adult neurogenesis in spatial long-term memory. Neuroscience 2005, 130:843852.

40. Jaako-Movits K, Zharkovsky A: Impaired fear memory and decreased hippocampal neurogenesis following olfactory bulbectomy in rats. The European journal of neuroscience 2005, 22:2871-2878.

41. Kriegstein AR, Noctor SC: Patterns of neuronal migration in the embryonic cortex. Trends in neurosciences 2004, 27:392-399.

42. Wichterle $H$, Turnbull DH, Nery S, Fishell G, Alvarez-Buylla A: In utero fate mapping reveals distinct migratory pathways and fates of neurons born in the mammalian basal forebrain. Development 2001, 128:3759-3771.

43. Wichterle H, Garcia-Verdugo JM, Herrera DG, Alvarez-Buylla A: Young neurons from medial ganglionic eminence disperse in adult and embryonic brain. Nat Neurosci 1999, 2:461-466.

44. Pleasure SJ, Anderson S, Hevner R, Bagri A, Marin O, Lowenstein DH, Rubenstein $J$ : Cell migration from the ganglionic eminences is required for the development of hippocampal GABAergic interneurons. Neuron 2000, 28:727-740.

45. Inta D, Alfonso J, von Engelhardt J, Kreuzberg MM, Meyer AH, van Hooft JA, Monyer $\mathrm{H}$ : Neurogenesis and widespread forebrain migration of distinct GABAergic neurons from the postnatal subventricular zone. Proc Natl Acad Sci USA 2008, 105:20994-20999.

46. Cobos I, Calcagnotto ME, Vilaythong AJ, Thwin MT, Noebels JL, Baraban SC, Rubenstein $J$ : Mice lacking Dlx1 show subtype-specific loss of interneurons, reduced inhibition and epilepsy. Nat Neurosci 2005, 8:10591068.

47. Gant JC, Thibault O, Blalock EM, Yang J, Bachstetter A, Kotick J, Schauwecker PE, Hauser KF, Smith GM, Mervis R, Li Y, Barnes GN: Decreased number of interneurons and increased seizures in neuropilin
2 deficient mice: Implications for autism and epilepsy. Epilepsia 2008, 50(4):629-45, 2009.

48. Bozzi Y, Vallone D, Borrelli E: Neuroprotective role of dopamine against hippocampal cell death. J Neurosci 2000, 20:8643-8649.

49. Mita AC, Mita MM, Nawrocki ST, Giles FJ: Survivin: key regulator of mitosis and apoptosis and novel target for cancer therapeutics. Clin Cancer Res 2008, 14:5000-5005.

50. Seri B, Garcia-Verdugo JM, Collado-Morente L, McEwen BS, Alvarez-Buylla A: Cell types, lineage, and architecture of the germinal zone in the adult dentate gyrus. The Journal of comparative neurology 2004, 478:359-378.

51. Ge S, Pradhan DA, Ming GL, Song H: GABA sets the tempo for activitydependent adult neurogenesis. Trends in neurosciences 2007, 30:1-8.

52. Balu DT, Lucki I: Adult hippocampal neurogenesis: regulation, functional implications, and contribution to disease pathology. Neuroscience and biobehavioral reviews 2009, 33:232-252.

53. Imayoshi I, Sakamoto M, Ohtsuka T, Takao K, Miyakawa T, Yamaguchi M, Mori K, Ikeda T, Itohara S, Kageyama R: Roles of continuous neurogenesis in the structural and functional integrity of the adult forebrain. Nat Neurosci 2008, 11:1153-1161.

54. Dusek JA, Eichenbaum $\mathrm{H}$ : The hippocampus and memory for orderly stimulus relations. Proc Natl Acad Sci USA 1997, 94:7109-7114.

55. Rossi C, Angelucci A, Costantin L, Braschi C, Mazzantini M, Babbini F, Fabbri ME, Tessarollo L, Maffei L, Berardi N, Caleo M: Brain-derived neurotrophic factor (BDNF) is required for the enhancement of hippocampal neurogenesis following environmental enrichment. The European journal of neuroscience 2006, 24:1850-1856.

56. Mandyam CD, Harburg GC, Eisch AJ: Determination of key aspects of precursor cell proliferation, cell cycle length and kinetics in the adult mouse subgranular zone. Neuroscience 2007, 146:108-122.

57. Schanzer A, Wachs FP, Wilhelm D, Acker T, Cooper-Kuhn C, Beck H, Winkler J, Aigner L, Plate KH, Kuhn HG: Direct stimulation of adult neural stem cells in vitro and neurogenesis in vivo by vascular endothelial growth factor. Brain Pathol 2004, 14:237-248.

58. Simeone A, Acampora D, Pannese M, D'Esposito M, Stornaiuolo A, Gulisano M, Mallamaci A, Kastury K, Druck T, Huebner K, et al: Cloning and characterization of two members of the vertebrate Dlx gene family. Proc Natl Acad Sci USA 1994, 91:2250-2254

59. Wuenschell CW, Fisher RS, Kaufman DL, Tobin AJ: In situ hybridization to localize mRNA encoding the neurotransmitter synthetic enzyme glutamate decarboxylase in mouse cerebellum. Proc Natl Acad Sci USA 1986, 83:6193-6197.

60. Szabo G, Kartarova Z, Hoertnagl B, Somogyi R, Sperk G: Differential regulation of adult and embryonic glutamate decarboxylases in rat dentate granule cells after kainate-induced limbic seizures. Neuroscience 2000, 100:287-295.

61. Conway EM, Pollefeyt S, Cornelissen J, DeBaere I, Steiner-Mosonyi M, Ong K, Baens M, Collen D, Schuh AC: Three differentially expressed survivin CDNA variants encode proteins with distinct antiapoptotic functions. Blood 2000, 95:1435-1442

62. Tiveron MC, Hirsch MR, Brunet JF: The expression pattern of the transcription factor Phox2 delineates synaptic pathways of the autonomic nervous system. J Neurosci 1996, 16:7649-7660.

63. Schauwecker PE, Steward O: Genetic determinants of susceptibility to excitotoxic cell death: implications for gene targeting approaches. Proc Natl Acad Sci USA 1997, 94:4103-4108.

64. Hogg S: A review of the validity and variability of the elevated plusmaze as an animal model of anxiety. Pharmacology, biochemistry, and behavior 1996, 54:21-30.

65. Miyakawa T, Yamada M, Duttaroy A, Wess J: Hyperactivity and intact hippocampus-dependent learning in mice lacking the M1 muscarinic acetylcholine receptor. J Neurosci 2001, 21:5239-5250.

66. Picciotto MR, Wickman K: Using knockout and transgenic mice to study neurophysiology and behavior. Physiological reviews 1998, 78:1131-1163.

67. Paradee W, Melikian HE, Rasmussen DL, Kenneson A, Conn PJ, Warren ST: Fragile $\times$ mouse: strain effects of knockout phenotype and evidence suggesting deficient amygdala function. Neuroscience 1999, 94:185-192.

68. Paylor R, Tracy R, Wehner J, Rudy JW: DBA/2 and C57BL/6 mice differ in contextual fear but not auditory fear conditioning. Behavioral neuroscience 1994, 108:810-817. 
69. Aloe L, Properzi F, Probert L, Akassoglou K, Kassiotis G, Micera A, Fiore M: Learning abilities, NGF and BDNF brain levels in two lines of TNF-alpha transgenic mice, one characterized by neurological disorders, the other phenotypically normal. Brain Res 1999, 840:125-137.

70. D'Hooge R, De Deyn PP: Applications of the Morris water maze in the study of learning and memory. Brain research 2001, 36:60-90.

doi:10.1186/1471-2202-11-2

Cite this article as: Coremans et al:: Impaired neurogenesis, learning and memory and low seizure threshold associated with loss of neural precursor cell survivin. BMC Neuroscience 2010 11:2.

Publish with Biomed Central and every scientist can read your work free of charge

"BioMed Central will be the most significant development for disseminating the results of biomedical research in our lifetime. " Sir Paul Nurse, Cancer Research UK

Your research papers will be:

- available free of charge to the entire biomedical community

- peer reviewed and published immediately upon acceptance

- cited in PubMed and archived on PubMed Central

- yours - you keep the copyright 